\title{
CCR4 expression on host T cells is a driver for alloreactive responses and lung rejection
}

\author{
Vyacheslav Palchevskiy, ${ }^{1}$ Ying Ying Xue, ${ }^{1}$ Rita Kern, ${ }^{1}$ Stephen S. Weigt, ${ }^{1}$ Aric L. Gregson, ${ }^{1}$ \\ Sophie X. Song, ${ }^{1}$ Michael C. Fishbein, ${ }^{1}$ Cory M. Hogaboam, ${ }^{2}$ David M. Sayah, ${ }^{1}$ Joseph P. Lynch III, ${ }^{1}$ \\ Michael P. Keane, ${ }^{3}$ David G. Brooks, ${ }^{4}$ and John A. Belperio ${ }^{1}$ \\ 'Department of Medicine, David Geffen School of Medicine, UCLA, Los Angeles, California, USA. ${ }^{2}$ Pulmonary \& Critical \\ Care Medicine, Cedars-Sinai Medical Center, Los Angeles, California, USA. ${ }^{3}$ University College Dublin School of Medicine, \\ Respiratory Medicine, St Vincent's University Hospital, Dublin, Ireland. ${ }^{4}$ Princess Margaret Cancer Center, University Health \\ Network and Department of Immunology, University of Toronto, Toronto, Ontario, Canada.
}

Despite current immunosuppressive strategies, long-term lung transplant outcomes remain poor due to rapid allogenic responses. Using a stringent mouse model of allo-airway transplantation, we identified the CCR4-ligand axis as a central node driving secondary lymphoid tissue homing and activation of the allogeneic T cells that prevent long-term allograft survival. CCR4 deficiency on transplant recipient T cells diminished allograft injury and when combined with CTLA4-Ig led to lung allograft accommodation lasting longer than in any previous study to our knowledge. Thus, we identify CCR4-ligand interactions as a central mechanism driving allogeneic transplant rejection and suggest it as a potential target to enhance long-term lung transplant survival.

Conflict of interest: The authors have declared no conflict of interest exists.

Copyright: (c) 2019, American Society for Clinical Investigation.

Submitted: May 1, 2018

Accepted: May 8, 2019

Published: June 20, 2019.

Reference information: JCI Insight. 2019;4(12):e121782. https://doi. org/10.1172/jci.insight.121782.

\section{Introduction}

Lung transplants have among the worst overall long-term clinical outcomes, with a 5 year survival of less than $55 \%$ (1). This is particularly concerning when compared with other solid organ transplants such as liver, kidney, and heart that have 5-year survival rates of at least 70\% (1-6). Lung transplant recipients also have much higher rates of rejection, the main risk factor for limited lung allograft survival (7-15). Rejection is classically considered a consequence of an immune response to donor alloantigens that results in allograft dysfunction (7-15). However, many of the molecular factors involved in the initiation of the alloresponse that leads to rejection remain largely unknown.

Rejection of solid organs involves alloresponsive lymphocytes and delayed-type hypersensitivity (DTH). The alloresponse begins with the homing of recipient-derived naive $\mathrm{T}(\mathrm{Tn})$ cells to secondary lymphoid tissues (SLTs). Once inside SLTs, Tn cells traffic intranodally to antigen-presenting cells (APCs), and this interaction generates allospecific $\mathrm{T}$ cells in a process called allopriming. The allospecific lymphocytes egress from the SLT, traffic to the transplanted organ, and release cytotoxic mediators that directly injure the allograft. The alloreactive lymphocytes also initiate a DTH response that directs waves of activated leukocytes into the allograft, further destroying the injured graft, ultimately leading to graft failure.

Many, but not all, studies have suggested that nontransplant $\mathrm{T}$ cell priming within lymph nodes is independent of chemokines due to the efficient scanning capabilities between Tn cells and APCs (16-27). This has led to a paucity of information involving the role of chemokines in orchestrating allopriming. Interestingly, we observed high levels of the chemokines CCL17 and CCL22 in draining lymph nodes following allograft transplantation using a stringent mouse model of heterotopically placed airway grafts. Considering that the receptor for these chemokines, CCR4, has been described on Tn cells (28-30), we sought to determine whether the CCR4-ligand biological axis mediates the alloreactive immune response following transplantation. Herein, we demonstrate that CCR4 expression on host-derived $\mathrm{T}$ cells is critical for their homing to draining lymph nodes and intranodal activation, which drives the alloreactive response involved in transplant rejection. CCR4 deletion on T cells reduced airway allograft rejection. Interestingly, CCR4 deficiency in combination with a short perioperative course of CTLA4-Ig enabled an unprecedented long-term allograft survival over 125 days compared with approximately 1 month when CTLA4-Ig was 
administered to $\mathrm{CCR}^{+/+}$recipients. This observation was corroborated in the fully vascularized murine left single-lung transplant model. Thus, we identify the CCR4-ligand axis as a critical checkpoint in driving the allogeneic response leading to transplant rejection and indicate a target for therapeutic intervention to maintain long-term organ survival.

\section{Results}

Draining SLT has increased CCL17 and CCL22 expression during allograft rejection. Previous studies have demonstrated that Tn cells express the CCR4 receptor while mononuclear phagocytes and APCs can be a rich source for its ligands CCL17 and CCL22 (28-30). We used the fully mismatched heterotopic tracheal transplant model of airway allograft rejection to explore the role of CCR4-ligand interaction in allograft rejection. BALB/c airways were transplanted subcutaneously into C57BL/6 recipients (allografts) and C57BL/ 6 airways into C57BL/6 recipients (isografts). This model of rejection is a highly reproducible and over time results in pathology that is representative of human acute rejection and chronic lung allograft dysfunction (31-35). A kinetic evaluation of CCR4 ligands from whole draining SLT (axillary and brachial nodes) homogenates using Luminex technology demonstrated marked elevation of both CCL17 and CCL22 protein concentrations on days 7 and 14 from allografts as compared with isografts (Figure 1A). We also determined the cellular sources of these chemokines by performing IHC analysis on allograft draining SLTs $(n=4)$ on day 7 after transplant. Morphometrically, we observed that CCL17 was predominately expressed by high endothelial venules (HEVs) in the paracortical areas (Figure 1B). CCL22 protein localized predominately to paracortical and subcapsular sinus mononuclear phagocytes (Figure 1C). These chemokine expression patterns are poised to work together in bringing Tn cells to SLTs as well as allowing them to traffic within the node to APCs.

The inhibition of CCR 4 interactions with its ligands profoundly attenuates allograft rejection. The increased levels of CCL17 and CCL22 in SLTs from allograft recipients suggested that perturbing the CCR4-ligand axis could inhibit allograft injury. To test this, BALB/c airways were transplanted into C57BL/6 CCR4 ${ }^{-/-}$or $\mathrm{CCR}^{+/+}$recipients, and the allografts were harvested at multiple time points for histopathological rejection scoring based on leukocyte infiltration, epithelial injury, matrix deposition, and fibro-obliteration $(32,33,36)$. $\mathrm{BALB} / \mathrm{c}$ donor airways prior to transplant demonstrated minimal inflammation, normal epithelium, and no matrix deposition or fibrosis (Figure $2 \mathrm{~A}$ ). $\mathrm{CCR} 4^{-/-}$recipients had profoundly lower rejection scores compared with $\mathrm{CCR}^{+/+}$recipients on days 7, 14, 21, and 28 (Figure 2, A and B, and Supplemental Figure 1A; supplemental material available online with this article; https://doi.org/10.1172/jci.insight.121782DS1). More specifically, allografts from $\mathrm{CCR} 4^{+/+}$recipients developed marked leukocyte infiltration with epithelial cell injury on day 7 , persistent inflammation with partially denuded epithelium and matrix deposition on day 14, and a denuded epithelium with invading fibroblasts obstructing the allograft airways on days 21 and 28. In contrast, airway allografts from $\mathrm{CCR} 4^{-/-}$recipient mice had mild to moderate inflammation, with a preserved epithelium and no significant matrix deposition or fibroblast obliteration throughout the 28-day time course (Figure 2, A and B, and Supplemental Figure 1A). Interestingly, a recent study suggests that CCR4 is required for $\mathrm{T}$ cell development; therefore, the $\mathrm{CCR} 4^{-/-}$recipient mice could have an altered $\mathrm{T}$ cell repertoire (37), which could be responsible for the reduction in allograft rejection. Thus, we performed confirmatory studies involving donor BALB/c airways transplanted into C57BL/6 recipients treated with either a CCR4 antagonist or an appropriate control. More specifically, recipient mice were treated with the small molecule CCR4 antagonist C 021 dihydrochloride at $50 \mathrm{mg} / \mathrm{kg}$ versus an appropriate control administered i.p. every day beginning on day -1 until allograft harvesting for rejection scoring on day 14 (38). The CCR4 antagonist led to similar reductions in rejection scores as in the CCR $4^{-/-}$recipients when compared with appropriate controls (Figure 2, C and D). These results suggest that the CCR $4^{-/-}$recipients' ability to attenuate allograft rejection is not due to an altered $\mathrm{CCR} 4^{-/-} \mathrm{T}$ cell repertoire or an altered microbiota.

CCR4 ligands have been implicated in the recruitment of APCs to draining SLTs (39). Furthermore, it has been established that donor-derived APCs can migrate from the transplanted organ to the recipient SLT, where they are involved in the initiation of rejection (40). To test the role of CCR4 on donor APCs, we transplanted donor airways from $\mathrm{C} 57 \mathrm{BL} / 6 \mathrm{CCR} 4^{-/-}$mice into $\mathrm{BALB} / \mathrm{c}$ recipients, so that only the donor-derived cells would lack CCR4. However, in this situation we did not observe any alterations in allograft rejection scores on days 7, 14, or 21; and CCR4 $4^{+/}$and CCR4 $4^{-/-}$donor airways allografts had similar amounts of infiltrating leukocytes, destroyed epithelium, and fibroblasts obstructing the airway (Supplemental Figure 1, B and C). Thus, CCR4 expression on host-derived cells participates in promoting allograft rejection. 
$C C R 4^{-1}$ SLTs have a reduction in the amount of $T$ cells during airway allograft rejection. Based on the HEVs and mononuclear phagocytes expressing CCL17 and CCL22 in allograft draining SLTs, we tested the chemokines' importance in driving $\mathrm{T}$ cell trafficking to lymph nodes following allograft transplantation. On day 7 after transplant, a time point with extensive leukocyte infiltration into the allograft $(32,33,36)$, we observed a significant reduction in total numbers of $\mathrm{CD}^{+}$and $\mathrm{CD} 8^{+} \mathrm{T}$ cells, as well as their subpopulations with central memory $\left(\mathrm{CD} 62 \mathrm{~L}^{+} \mathrm{CD} 44^{\mathrm{hi}}\right)$ and naive $\mathrm{T}$ cell $\left(\mathrm{CD} 62 \mathrm{~L}^{+} \mathrm{CD} 44^{\mathrm{lo} / \mathrm{neg}}\right)$ phenotypes from $\mathrm{CCR} 4^{-/}$ recipient lymph nodes as compared with controls (Figure 3, A-C). Interestingly, only the frequency of $\mathrm{CD}^{+} \mathrm{T}$ cells and their central memory and naive $\mathrm{T}$ cell phenotypes was reduced, while the frequency of $\mathrm{CD}^{+} \mathrm{T}$ cells and their subpopulations of central memory and naive $\mathrm{T}$ cell phenotypes was unchanged in $\mathrm{CCR}^{4^{-/}}$SLTs compared with CCR4 $4^{+/+}$controls (Figure 3, D-F, and Supplemental Figure 2, A-C). Some studies have shown that CCR4-expressing Tregs are important for tolerance $(41,42)$, while others have not (43). Thus, we evaluated the expression of Foxp3, a marker for Tregs $(41,42)$, in draining lymph node homogenates from the CCR $4^{-/}$recipients. There were reductions in Foxp3 mRNA expression by real-time quantitative PCR (qPCR) from the $\mathrm{CCR} 4^{-/-}$, as compared with $\mathrm{CCR} 4^{+/+}$, recipient lymph nodes on day 7 (Figure 3, G and H). These results suggest that inhibition of the interaction of CCR4 with its ligands can decrease Foxp3-expressing cells in SLTs during an allogeneic response. Overall, CCR4 deletion led to diminished T and Foxp3-expressing cells within SLTs following allograft transplantation.

CCR4 deficiency on T cells inhibits allograft rejection by preventing Tn cell homing and activation within draining SLTs. To probe whether CCR4 signaling specifically on T cells attenuates allograft rejection, we adoptively transferred $\mathrm{T}$ cells from $\mathrm{CCR} 4^{+/+}$or $\mathrm{CCR} 4^{-/-}$mice before transplant (day 0 ) into $\mathrm{CCR} 4^{+/+}$or $\mathrm{CCR}^{-/-}$recipients. Airway allografts in $\mathrm{CCR} 4^{-/}$recipients of $\mathrm{CCR} 4^{-/-} \mathrm{T}$ cells had limited rejection, while allograft rejection in $\mathrm{CCR} 4^{-/-}$recipients of adoptively transferred CCR4 ${ }^{+/+} \mathrm{T}$ cells was similar to that in $\mathrm{CCR}^{+/+}$recipients of $\mathrm{CCR} 4^{+/+} \mathrm{T}$ cells (Figure $4 \mathrm{~A}$ ). Analysis of the airway allograft tissue demonstrated that $\mathrm{CCR} 4^{-/-}$recipients with adoptive transfer of $\mathrm{CCR} 4^{-/-} \mathrm{T}$ cells had some intraluminal leukocyte infiltration as well as mucus with cytokeratin and leukocyte debris that was inherent to the heterotopic position of the airway graft (Figure 4B). Importantly, there was minimal epithelial cell injury without any substantial obstruction of the airway by fibroblasts (Figure 4B). In contrast, CCR $4^{-/-}$recipients with adoptive transfer of $\mathrm{CCR} 4^{+/+} \mathrm{T}$ cells were similar to $\mathrm{CCR} 4^{+/+}$recipients of CCR $4^{+/+} \mathrm{T}$ cells, in which we observed many intraluminal leukocytes and a denuded basement membrane with fibroblasts obstructing the airway (Figure 4B). Thus, CCR4 expression on T cells is critical for driving allograft rejection, while preventing CCR4-ligand interactions dramatically attenuates graft rejection.

Exploring mechanisms for CCR4-expressing $\mathrm{T}$ cell involvement in rejection, $\mathrm{CCR} 4^{+/+}$and $\mathrm{CCR}^{-/-} \mathrm{T}$ cells from naive mice were labeled and equal amounts transferred into day $7 \mathrm{CCR} 4^{+/+}$recipients of airway allografts. Eighteen hours after transfer, draining lymph nodes were harvested and processed into single-cell suspensions for labeled $\mathrm{T}$ cell analysis by flow cytometry. There were dramatic reductions in the frequency of labeled $\mathrm{CCR}^{-/-}$total $\mathrm{T}$ cells as well as $\mathrm{CD}^{+}$and $\mathrm{CD} 8^{+} \mathrm{T}$ cells in allograft draining nodes, as compared with labeled $\mathrm{CCR}^{+/+} \mathrm{T}$ cells and their subpopulations (Figure 4, C-E, and Supplemental Figure 3A). However, if there are certain genetic differences between the $\mathrm{CCR} 4^{-/-}$and $\mathrm{CCR} 4^{+/+} \mathrm{T}$ cells, it is possible that the endogenous and transferred CCR $4^{+/+} \mathrm{T}$ cells might reject cotransferred CCR4 ${ }^{-/-} \mathrm{T}$ cells, and this would result in reduced recovery of the CCR4 ${ }^{-/-} \mathrm{T}$ cells within the draining nodes. Thus, we performed the same cotransfer experiments using day $7 \mathrm{CCR} 4^{-/}$allograft recipients. Again, there were reductions in the frequency of labeled CCR $4^{-/-}$total $\mathrm{T}$ cells and $\mathrm{CD}^{+}$and $\mathrm{CD} 8^{+} \mathrm{T}$ cells in the $\mathrm{CCR}^{-/-}$allograft recipient draining nodes, as compared with labeled $\mathrm{CCR}^{+/+} \mathrm{T}$ cells and their subpopulations (Figure 4, C-E). However, this was not to the same magnitude found in the day $7 \mathrm{CCR}^{+/+}$recipients, likely due to lower degree of rejection found with the $\mathrm{CCR} 4^{-/-}$recipients. Furthermore, we found that CD62L was downregulated on the majority of labeled CCR $4^{+/+} \mathrm{CD} 4^{+}$and $\mathrm{CD} 8^{+}$ Tn cells in SLTs from the CCR $4^{+/+}$allograft recipients at 18 hours, while CD62L expression remained high on almost all of the labeled CCR $4^{-/} \mathrm{CD}^{+}$and $\mathrm{CD} 8^{+}$Tn cell subpopulations (Figure $4 \mathrm{~F}$ and Supplemental Figure $3 \mathrm{~B})$. There is a possibility that the downregulation of CD62L by CCR $4^{+/+} \mathrm{T}$ cells was due to their activation by the $\mathrm{CCR} 4^{-/}$cotransferred $\mathrm{T}$ cells if they have certain genetic differences from the CCR $4^{+/+} \mathrm{T}$ cells rather than being activated from alloantigens. Hence, we performed the same cotransfer experiment, but into day 7 isografts, and found there was no differences in CD62L expression, which remained high on most of the $\mathrm{CCR}^{+/+}$and $\mathrm{CCR} 4^{-/-}$labeled Tn cell subpopulations (Figure $4 \mathrm{~F}$ ), confirming that activation of $\mathrm{CCR}^{-/-}$as compared with $\mathrm{CCR}^{+/+} \mathrm{T}$ cells from alloantigens within the draining lymph node was impaired. Collectively, these experiments indicate that the $\mathrm{CCR}^{-/-} \mathrm{CD} 4^{+}$and $\mathrm{CD} 8^{+} \mathrm{Tn}$ cells during rejection have decreased ability 


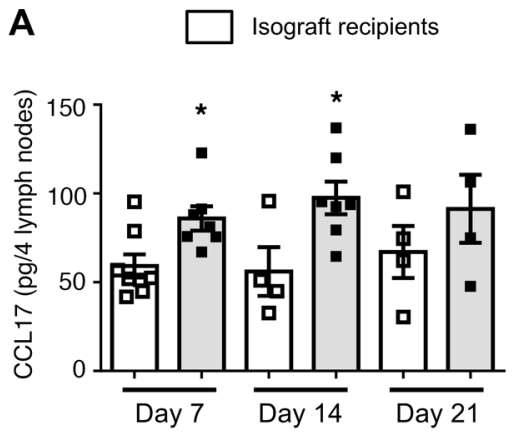

B

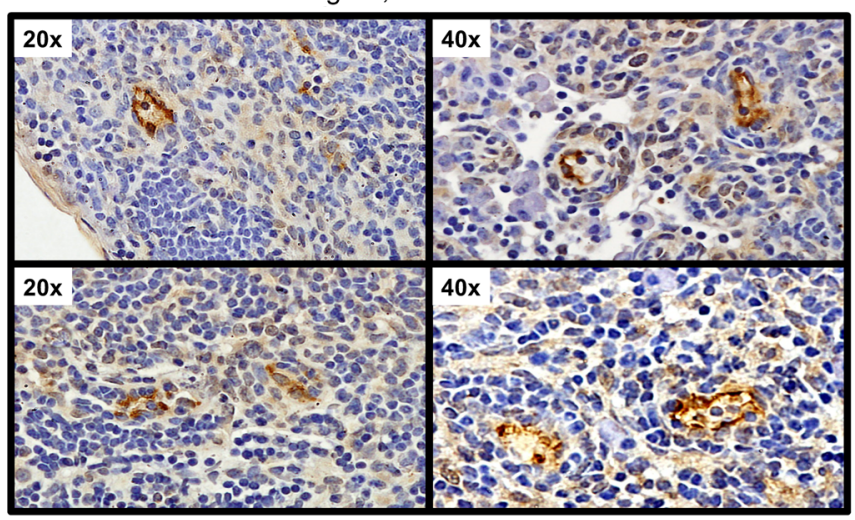

Sham-operated control, Anti-CCL17 Ab

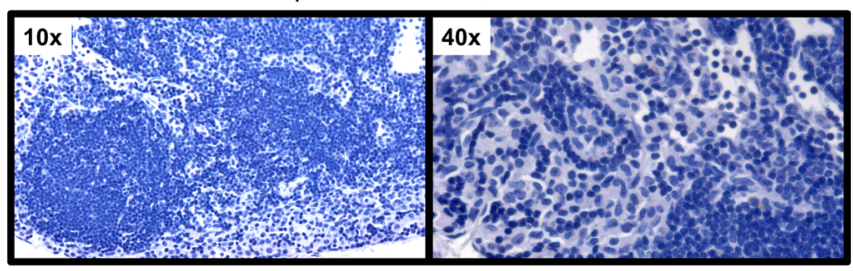

Allograft, Control $\mathrm{Ab}$

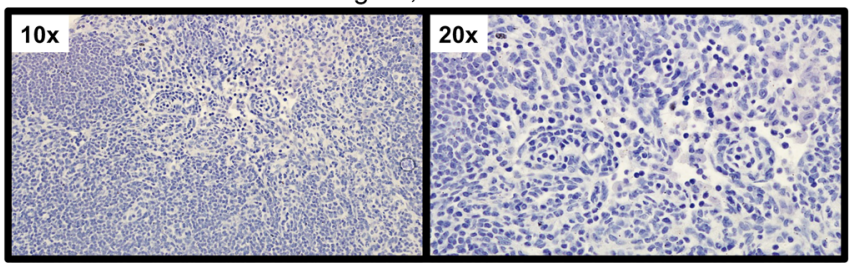

Allograft recipients

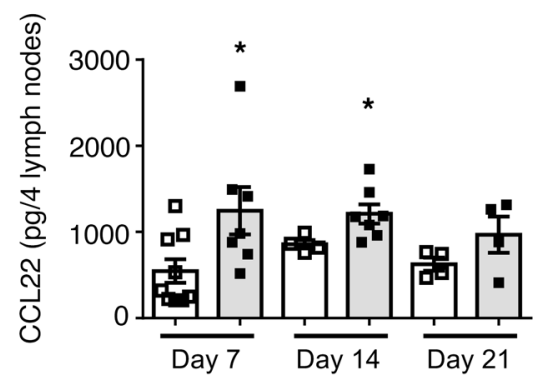

C

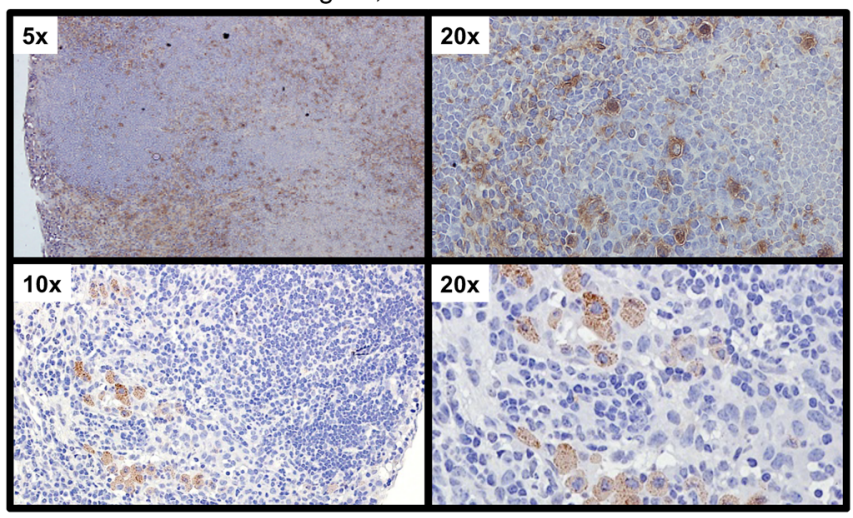

Sham-operated control, Anti-CCL22 Ab

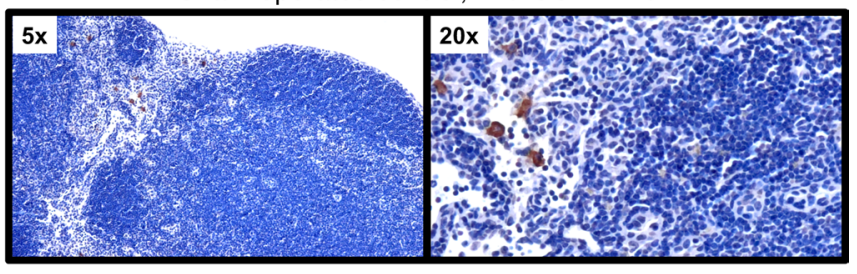

Allograft, Control Ab

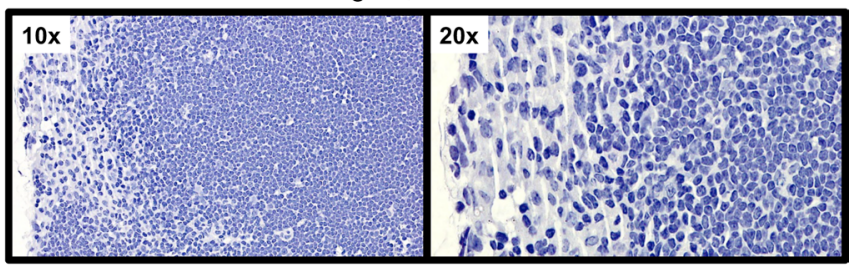

Figure 1. Draining allograft recipient lymph nodes have increased expression of CCL17 and CCL22. BALB/c airways were transplanted subcutaneously into C57BL/6 recipients (allografts), as compared with C57BL/6 airways transplanted into C57BL/6 recipients (isografts). Whole allograft draining nodes were harvested on days 7, 14, and 21 for protein analysis. (A) Protein concentrations of CCL17 and CCL22 by Luminex from whole draining node homogenates from allograft and isograft recipients. (B and C) Representative IHC staining for CCL17 and CCL22, as compared with appropriate control Abs from allograft draining lymph nodes or sham-operated CCR4 ${ }^{+/+}$mouse lymph nodes on day 7. Allograft recipient CCL17 protein is expressed morphologically from HEVs, as compared with virtually no staining in $\mathrm{CCR}^{+/+}$sham-operated controls or for the control Ab. In allograft recipients, CCL22 protein is detected morphologically on mononuclear phagocytes in the paracortical and subcapsular sinus, as compared with just a few mononuclear phagocytes only in the subcapsular sinus from the CCR4 ${ }^{+/+}$ sham-operated controls and virtually no staining for the control Ab. Protein data are representative of 4-9 mice per group. Error bars indicate SEM. Significance was determined by Mann-Whitney $U$ test; ${ }^{*} P<0.05$. IHC experiments involve $n=4$ nodes from 4 different allograft recipients.

to home to draining lymph nodes, and those CCR4 ${ }^{-/-} \mathrm{T}$ cells that do make it to the lymph nodes are not being efficiently activated against alloantigens from the airway allograft.

$C C R 4^{-1-}$ recipients have a reduction in alloresponsive $C D 4^{+}$and $C D 8^{+} T$ cells. The reduction in SLT homing and intranodal activation of $\mathrm{CD} 4^{+}$and $\mathrm{CD} 8^{+} \mathrm{Tn}$ cells following allograft transplantation suggests that $\mathrm{CCR} 4^{-/-} \mathrm{T}$ cells would also exhibit decreased effector function. To test this assumption, cells were isolated 
A

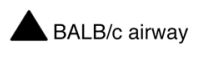
$\square_{\text {CCR } 4+/+ \text { recipients }}^{\text {BALB/c airway }}$

BALB/c airway $\longrightarrow$ CCR4-/- recipients

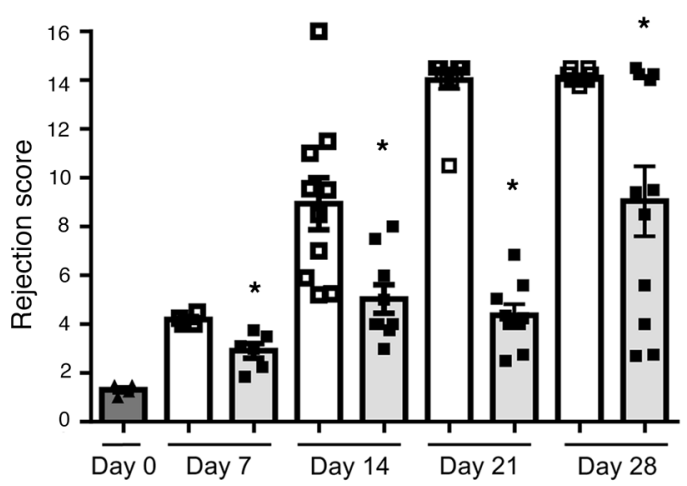

B

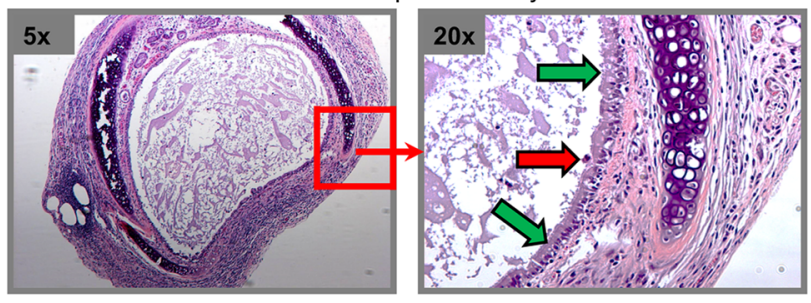

CCR4+/+ recipient at Day 21

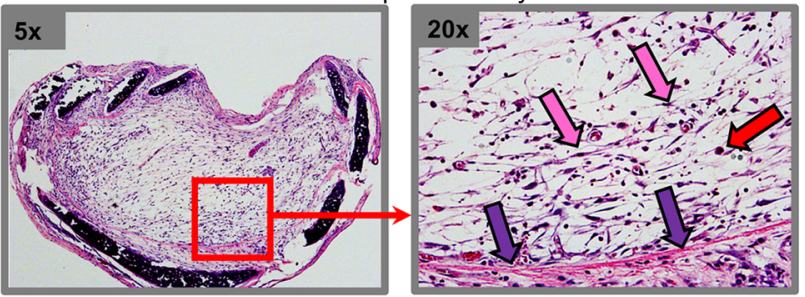

C

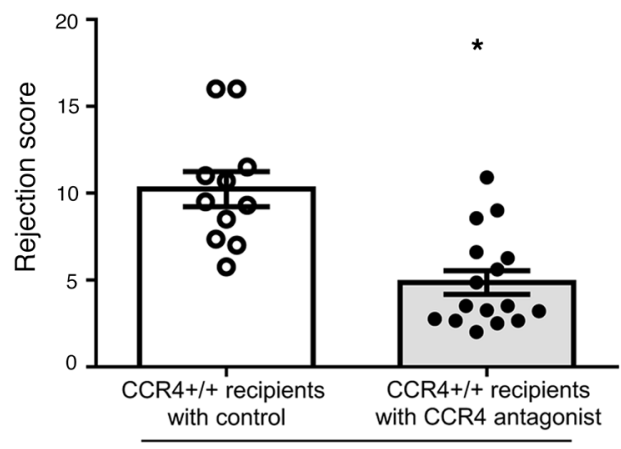

Day 14
D $\quad$ CCR4+/+ recipents with CCD4 antagonist at Day 14

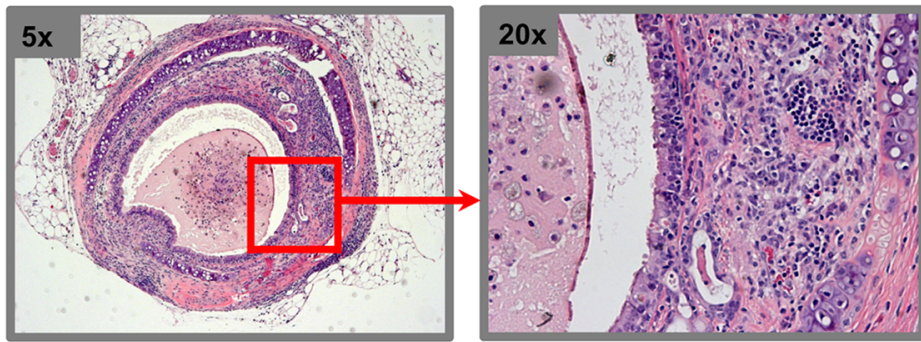

CCR4+/+ recipents with control at Day 14

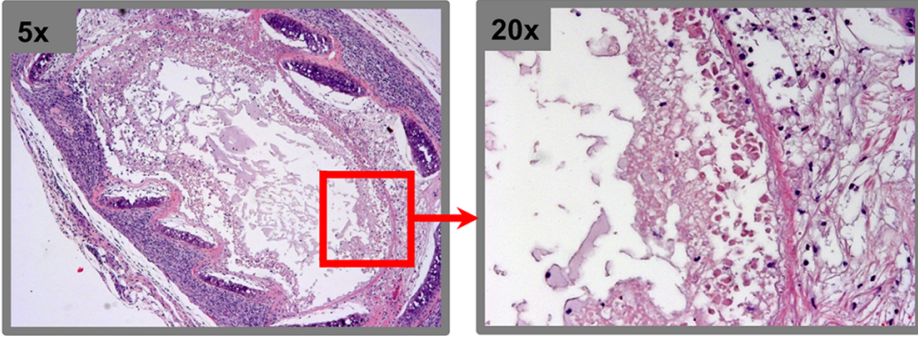

Figure 2. CCR4 ${ }^{-/-}$recipients of airway allografts attenuate rejection. BALB/C airways subcutaneously transplanted into CCR $^{-/-}$and CCR4 $4^{+/+}$recipients and their allografts were analyzed for rejection scores. (A) Rejection scores for donor BALB/c airways as well as allografts from either the CCR4 ${ }^{-/-}$or CCR4 ${ }^{+/+}$ recipients on days 7, 14, 21, and 28. (B) Representative H\&E staining of allografts from CCR4 ${ }^{-/-}$and CCR4 $4^{+/}$recipients on day 21 . CCR4 ${ }^{-/-}$recipients have limited intraluminal inflammation (red arrows), virtually normal epithelium (green arrows), and minimal matrix deposition without fibroblasts obstructing the lumen (i.e., fibro-obliteration). A section of the allograft is magnified to highlight the presence of a normal epithelial layer in the airway allografts from the CCR4 ${ }^{-/-}$recipients. Allografts from the CCR4 ${ }^{+/+}$recipients have a moderate amount of intraluminal inflammatory cells (red arrows), absence of airway epithelial cells (purple arrows), and presence of fibroblasts (pink arrows) causing fibro-obliteration of the lumen. See also Supplemental Figure 1. (C) Rejection scores of allografts from recipients treated with either the CCR4 antagonist or appropriate control on day 14. (D) Representative H\&E staining of allografts from the CCR4 antagonist and control on day 14. Recipients with the CCR4 antagonist have a virtually normal epithelium and minimal matrix deposition without fibro-obliteration. A section of the allograft is magnified to show the presence of a normal epithelial layer in the airway allografts from the recipients treated with the CCR4 antagonist. Allografts from the control-treated recipients have an absence of airway epithelial cells. Original magnification, $\times 5$. Error bars indicate SEM. Significance was determined by Mann-Whitney $U$ or unpaired $t$ test where appropriate; ${ }^{*} P<0.05$.

from draining SLTs 7 days after allograft transplantation from CCR $4^{-/-}$and CCR $4^{+/+}$recipients and stimulated with irradiated BALB/c splenocytes. In response to allostimulation, $\mathrm{CCR} 4^{+/+} \mathrm{CD} 4^{+}$and $\mathrm{CD} 8^{+} \mathrm{T}$ cells readily produced high amounts of IFN- $\gamma$ (Figure $4 \mathrm{G}$ and Supplemental Figure 4A). Strikingly, CD $4^{+}$and $\mathrm{CD} 8^{+} \mathrm{T}$ cells from CCR $4^{-/-}$mice produced almost no IFN- $\gamma$ in response to allostimulation, despite the graft having been transplanted 7 days earlier (Figure 4G and Supplemental Figure 4A). Importantly, CCR4-/ and $\mathrm{CCR} 4^{+/+} \mathrm{SLT} \mathrm{CD}^{+}$and $\mathrm{CD} 8^{+} \mathrm{T}$ cells from naive mice exhibited similar responses to the superantigen staphylococcal enterotoxin B with regard to IFN- $\gamma$ production, demonstrating that $\mathrm{CCR} 4^{-/-} \mathrm{T}$ cells do not have an intrinsic activation defect (Supplemental Figure 4, B and C). 

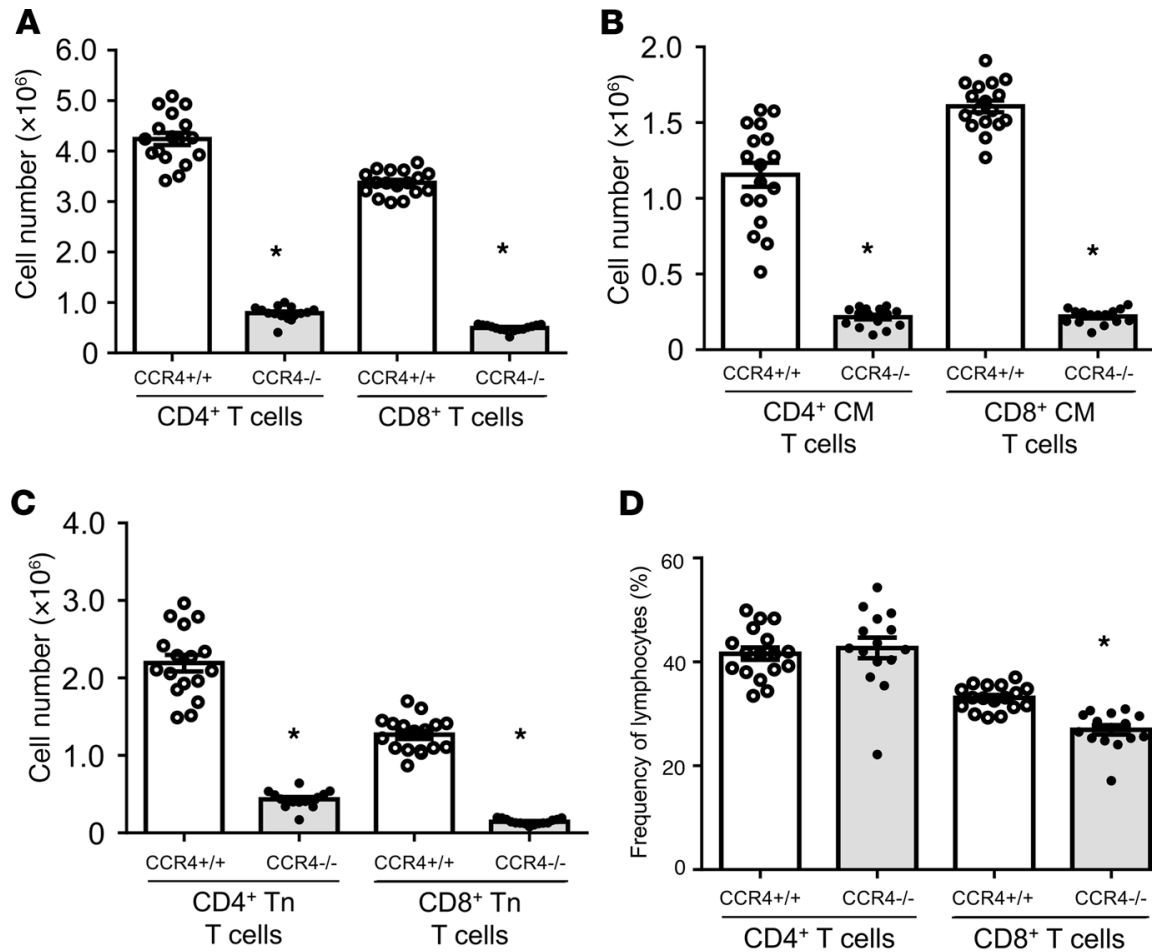

E

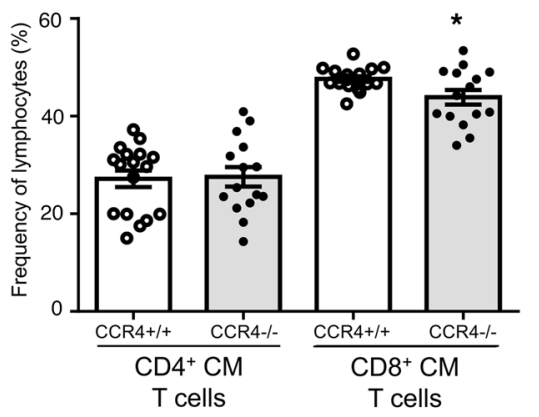

G

Foxp-3

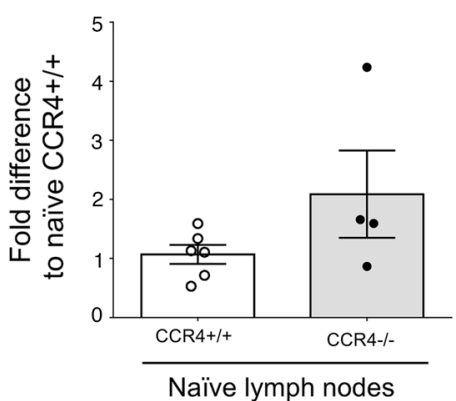

D

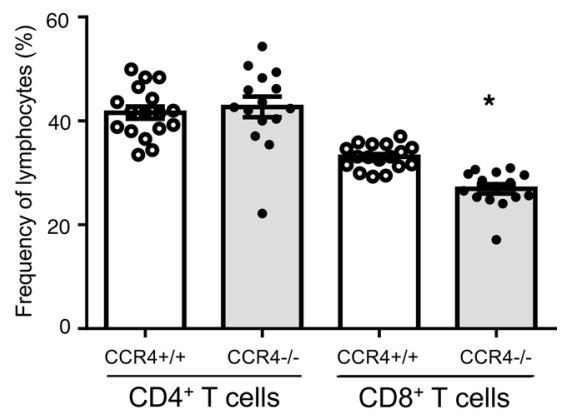

$\mathbf{F}$

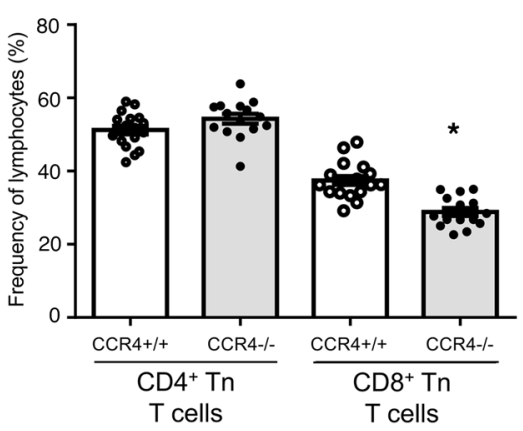

H

Foxp-3

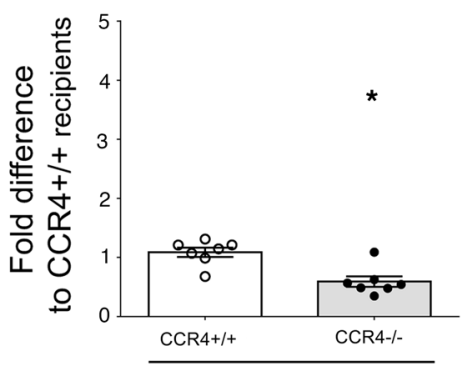

Allograft lymph nodes at Day 7
Figure 3. CCR4 ${ }^{-/-}$recipients of airway allografts attenuate rejection and have a reduction of $T$ cells in their draining lymph nodes. As described for Figure 2, BALB/c airways subcutaneously transplanted into $\mathrm{CCR} 4^{-/-}$and $\mathrm{CCR} 4^{+/+}$ recipients, and their whole draining lymph nodes were analyzed for $T$ cell subpopulations via flow cytometry. (A-F) Total number and frequency of $\mathrm{CD} 4^{+}$and $\mathrm{CD} 8^{+} \mathrm{T}$ cells and their naive $(\mathrm{Tn})$ and central memory (CM) T cell subpopulations from $\mathrm{CCR}^{+/+}$and $\mathrm{CCR}^{-/-}$allograft recipient lymph nodes on day 7. See also Supplemental Figure 2. (G) Lymph node expression of Foxp3 by QPCR for naive nontransplanted CCR4 ${ }^{+/+}$and CCR4 $4^{-/-}$mouse nodes as well as (H) $\mathrm{CCR}^{+/+}$and CCR4 ${ }^{-/-}$allograft recipient nodes on day 7. Data are representative of 4-15 mice per group. Error bars indicate SEM. Significance was determined by Mann-Whitney $U$ or unpaired $t$ test where appropriate; ${ }^{*} P<0.05$.

To further test the induction of the allograft response, we used an in vivo DTH response to alloantigens as a physiologic readout of alloprimed cells $(44,45)$. Irradiated BALB/c splenocytes were administered intradermally to the pinnae of (i) $\mathrm{CCR} 4^{-/-}$allograft recipients on day 7 after transplant; (ii) $\mathrm{CCR}^{+/+}$allograft recipients on day 7 after transplant; (iii) naive CCR4 $4^{-/-}$mice; or (iv) naive $\mathrm{CCR} 4^{+/+}$ mice. CCR $4^{-/-}$allograft recipients displayed a markedly reduced DTH response compared with CCR $4^{+/+}$ allograft recipients (Figure $4 \mathrm{H}$ ). Furthermore, the response was reduced to the level of that seen in naive $\mathrm{CCR}^{-/-}$and naive $\mathrm{CCR}^{+/+}$mice (Figure $4 \mathrm{H}$ ), indicating minimal functionally active alloresponsive $\mathrm{T}$ cells in the absence of CCR4 expression. 

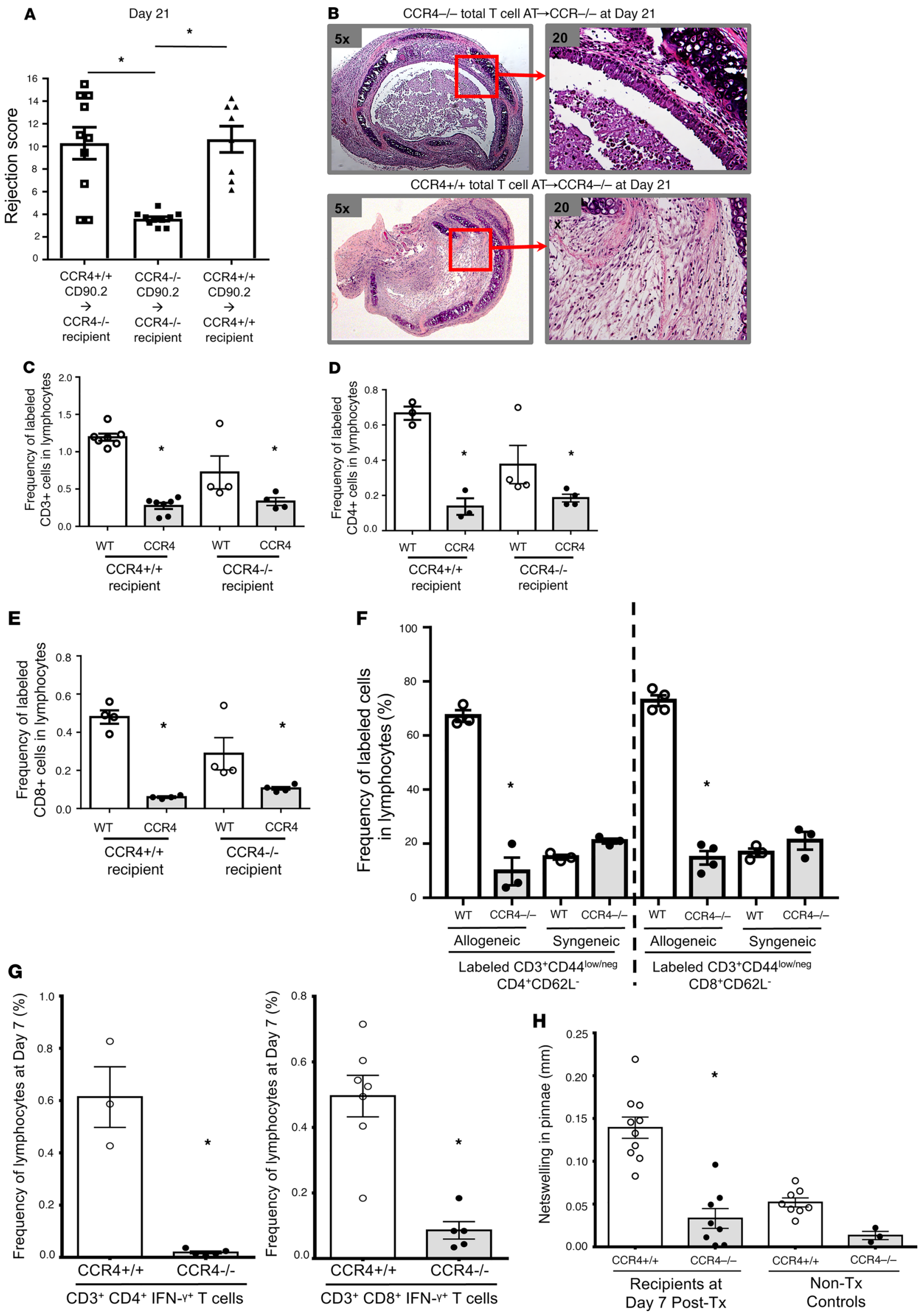
Figure 4. CCR4 expression is involved in naive T cell homing and intranodal activation. CD90.2 $\left(1 \times 10^{7}\right) \mathrm{T}$ cells from either CCR4 ${ }^{-/-}$or CCR4 $4^{+/}$naive mice were transferred to either CCR4 ${ }^{-/-}$or CCR4 ${ }^{+/}$recipients on day 0 , and the allografts were analyzed for rejection scores on day 21. (A) Rejection scores. (B) Representative H\&E staining showing that the transfer of CCR4 $4^{++} \mathrm{T}$ cells to CCR4 $4^{-/-}$recipients leads to severe rejection, with a denuded epithelium and fibro-obliteration. However, the transfer of CCR4 ${ }^{-1-}$ T cells to CCR4 ${ }^{-/-}$recipients causes no significant epithelial injury or fibro-obliteration. Original magnification, $\times 5$. AT, adoptive transfer. In separate experiments, CFSE-labeled T cells from CCR4 ${ }^{++}\left(4.0 \mu \mathrm{M}, 5 \times 10^{6}\right)$ and CCR4 ${ }^{-/-}\left(0.25 \mu \mathrm{M}, 5 \times 10^{6}\right)$ naive mice were transferred at a 1:1 ratio into day 7 CCR4 ${ }^{+/+}$and CCR4 ${ }^{-/-}$allograft or isograft (C57BL/6 airways to C57BL/6 recipients) recipients, and 18 hours later the draining nodes were analyzed for the frequency of labeled T cells as well as their activation based on CD62L shedding using flow cytometry. (C-E) Frequency of labeled CCR4 ${ }^{-/-}$and CCR4 $4^{+/+} \mathrm{CD}^{+}$, CD4 ${ }^{+}$, and $\mathrm{CD} 8^{+} \mathrm{T}$ cells. See also Supplemental Figure 3. (F) Frequency of labeled $\mathrm{CD} 4^{+}$and $\mathrm{CD} 8^{+} \mathrm{T}$ cells from $\mathrm{CCR} 4^{-{ }^{-}}$and $\mathrm{CCR} 4^{+/+}$naive mice that entered the lymph nodes and lost CD62L expression. See also Supplemental Figure 3. (C) Day 7 CCR4 ${ }^{-/-}$and CCR4 ${ }^{+/+}$allograft recipients' draining lymph node cells $\left(1 \times 10^{6}\right)$ were challenged with $\left(2 \times 10^{6}\right)$ irradiated BALB/c splenocytes and 16 hours later analyzed for alloresponsive CD4+ and CD8 ${ }^{+}$T cells via IFN- $\gamma$ secretion. See also Supplemental Figure 4. (H) Day 7 CCR4 ${ }^{-/-}$and CCR4 ${ }^{+/}$allograft recipients were challenged with $\left(7.5 \times 10^{6}\right)$ irradiated BALB/c splenocytes with an intradermal injection into the pinna and analyzed for DTH response at 48 hours. Data are representative of 3-12 mice per group. Error bars indicate SEM. Significance was determined by Mann-Whitney $U$ test, unpaired $t$ test, or Kruskal-Wallis with post hoc Dunn's test where appropriate; ${ }^{*} P<0.05$.

We further explored the downstream effects of CCR4-ligand inhibition on $\mathrm{T}$ cell function within the airway allograft. Interestingly, the frequency of allograft-infiltrating $\mathrm{CD} 4^{+} \mathrm{T}$ cells in CCR4 $4^{--}$mice was significantly increased, whereas the frequency of CCR $4^{-/} \mathrm{CD} 8^{+} \mathrm{T}$ cells was markedly decreased compared with $\mathrm{CCR} 4^{+/+}$mice 7 days after allograft transplantation (Figure 5A). Upon further analysis, there was no difference in $\mathrm{CD} 44^{\mathrm{hi}} \mathrm{CD} 4^{+} \mathrm{CD} 62 \mathrm{~L}^{-} \mathrm{T}$ cells and a reduction in the frequency of $\mathrm{CD} 44^{\mathrm{hi}} \mathrm{CD} 8^{+} \mathrm{CD} 62 \mathrm{~L}^{-} \mathrm{T}$ cells in allografts from $\mathrm{CCR} 4^{-/-}$recipients as compared with $\mathrm{CCR} 4^{+/+}$recipients (Figure 5B). Furthermore, protein levels of IL-2, TNF- $\alpha$, and IFN- $\gamma$ and mRNA levels of the T cell killing effectors FasL and perforin 1 were also decreased in the airway allografts of $\mathrm{CCR} 4^{-/-}$mice as compared with $\mathrm{CCR} 4^{+/+}$recipients (Figure $5, \mathrm{C}-\mathrm{G}$ ). In contrast, there was no significant difference in the mRNA expression of Foxp3 in airway allografts from CCR $4^{-/-}$and CCR $4^{+/+}$ recipients (Figure $5 \mathrm{H}$ ). Thus, in the absence of CCR4 expression, there was a dramatically diminished ability for $\mathrm{T}$ cells to mount functional responses against airway allografts, despite being present in the transplanted tissue.

Allograft rejection is dependent on help from $C C R 4^{+/+} C D 4^{+} T$ cells, not NKT or $C C R 4^{+/+} C D 8^{+} T$ cells. A recent study has demonstrated that NKT cell help, via a CCR4-dependent mechanism, is important during OVA sensitization (26), and this may apply to allograft rejection. However, we observed no difference in airway rejection scores on days 7 and 21 between Cd1d1 ${ }^{-/-}$recipients that lacked NKT cells as compared with Cd1d1 $1^{+/+}$recipients (Supplemental Figure 5, A and B). To determine whether other subsets of $\mathrm{T}$ cells functioned via a CCR4-dependent mechanism to induce allograft rejection, we adoptively transferred CCR $4^{+/+}$ $\mathrm{CD}^{+} \mathrm{T}$ cells, $\mathrm{CD} 8^{+} \mathrm{T}$ cells, or total $\mathrm{T}$ cells into $\mathrm{CCR} 4^{-/-}$recipients just prior to airway transplantation. On day 21 after transplant, CCR4 $4^{-/-}$recipients of $\mathrm{CCR} 4^{+/+}$or $\mathrm{CCR} 4^{-/-} \mathrm{CD} 8^{+} \mathrm{T}$ cells exhibited a similarly low rejection score (Figure 6A and Supplemental Figure 5C). Interestingly, CCR4 $4^{-/}$recipients of CCR $4^{+/+}$ $\mathrm{CD}^{+} \mathrm{T}$ cells reestablished a significant portion of alloreactivity, with rejection scores markedly greater than with transfer of $\mathrm{CCR} 4^{--} \mathrm{CD} 4^{+} \mathrm{T}$ cells, but not as high as the scores found with the transfer of total $\mathrm{T}$ cells to the $\mathrm{CCR} 4^{-/-}$recipients (Figure $6, \mathrm{~B}$ and C). Furthermore, when $\mathrm{CCR} 4^{+/+} \mathrm{CD} 4^{+} \mathrm{T}$ cells were transferred to $\mathrm{CCR} 4^{-/-}$recipients with either control $\mathrm{Ab}$ or the depleting anti-CD8 Ab delivered on days $-1,7$, and 14, there was a reduction in rejection scores in the anti-CD8 Ab-treated group on day 21 (Figure 6, D and E). Collectively, these results imply that maximal allograft rejection is present when CCR4 expression is on both $\mathrm{CD}^{+}$and $\mathrm{CD} 8^{+} \mathrm{T}$ cells and suggest that CCR4-expressing $\mathrm{CD} 4^{+} \mathrm{T}$ cells can directly cause a degree of allograft injury as well as provide help to $\mathrm{CD} 8^{+} \mathrm{T}$ cells during allograft rejection.

CCR4 deletion in combination with CTLA4-Ig leads to long-term airway and lung allograft accommodation. The combination of anti-CD154 (CD40L) with CTLA4-Ig to inhibit T cell priming is considered the preeminent combination for inducing long-term allograft accommodation (46). Therefore, we hypothesized that the therapeutic potential of CCR4-ligand inhibition by decreasing $\mathrm{T}$ cell priming and activation may be similar to that of anti-CD154 for enhancing CTLA4-Ig immunotherapy. Accordingly, we evaluated the effects on allograft survival of CTLA4-Ig therapy in CCR4 ${ }^{-/-}$allograft recipients. CTLA4-Ig $(0.2 \mathrm{mg})$ i.p. was given on day 0 prior to transplant and on days 2,4 , and 6 after transplant to $\mathrm{CCR} 4^{-/-}$or $\mathrm{CCR} 4^{+/+}$recipients of BALB/c airways. Strikingly, allograft airways from the CCR $4^{-/}$recipients were virtually normal on days 42 and 126 , whereas allograft airways from the $\mathrm{CCR} 4^{+/+}$recipients were completely rejected and fibro-obliterated by day 42 (Figure 7, A and B, and Supplemental Figure 6A). Thus, CCR4 deficiency in combination with a short perioperative course of CTLA4-Ig enabled long-term allograft survival in a situation that normally leads to rejection in a month.

We next performed proof-of-concept studies using the fully mismatched, vascularized left single-lung transplant model via the same stringent strain combination (BALB/c lung to C57BL/6 recipients) as the airway allograft model to corroborate our results. Lung allografts in $\mathrm{CCR} 4^{+/+}$recipient mice treated with CTLA4-Ig 


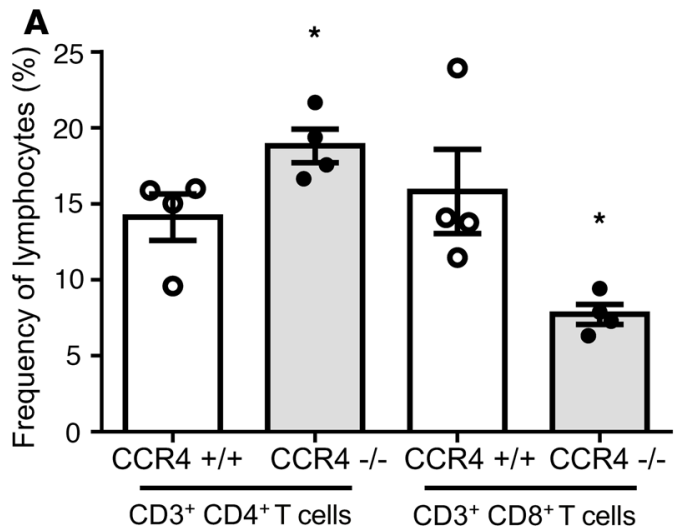

C

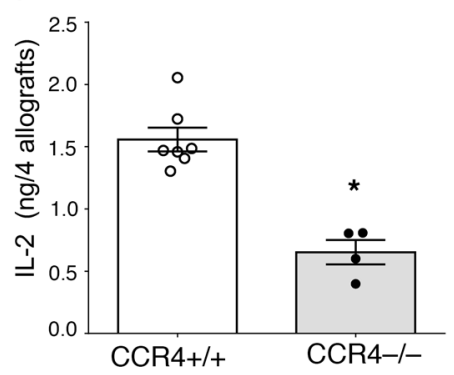

F

FasL

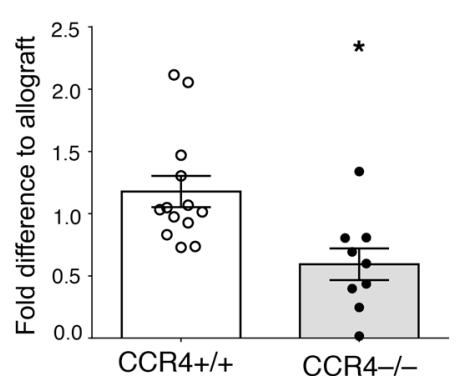

D
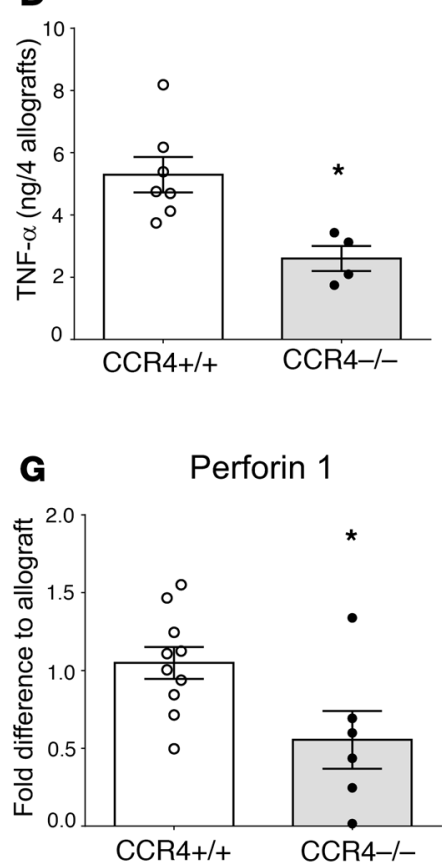

B

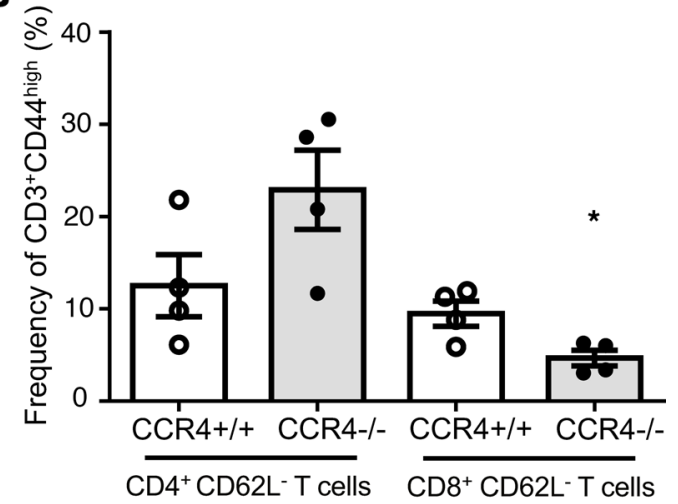

E

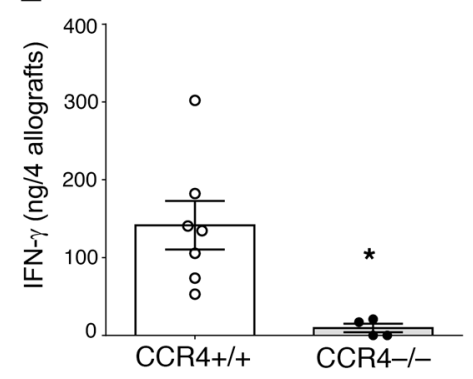

H

Foxp-3

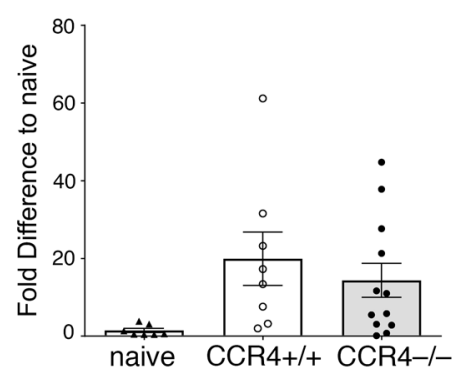

Figure 5. CCR4 ${ }^{-/-}$recipients have a reduction in airway allograft-infiltrating cytotoxic lymphocytes and their mediators. Day 7 whole airway allografts from $\mathrm{CCR}^{-/-}$and CCR4 ${ }^{+/+}$recipients were analyzed for allograft-infiltrating T cell subpopulations and cytotoxic mediators using flow cytometry, Luminex, and qPCR. (A and B) Frequency of allograft-infiltrating $C D 4^{+}$and $C D 8^{+} T$ cells as well as their subpopulations. (C-E) Whole allograft homogenates protein concentrations for IL-2, TNF- $\alpha$, and IFN- $\gamma$. (F-H) Whole allograft homogenate mRNA expression of FasL, perforin 1, and Foxp3. Data are representative of 4-7 mice per group. Error bars indicate SEM. Significance was determined by Mann-Whitney $U$ test; ${ }^{*} P<0.05$.

$(0.1 \mathrm{mg})$ i.p. just prior to transplant developed severe grade A rejection (acute rejection $[\mathrm{AR}] \geq 3$ ) with or without vasculitis, severe grade $B$ rejection $(B \geq 3)$ with high-grade infiltrates and epithelial cell injury, and severe pleural and septal inflammation with and without fibrosis by day 126 after transplant (Figure 7C). In contrast, CCR $4^{-1}$ recipients treated with the same single dose of pretransplant CTLA4-Ig $(0.1 \mathrm{mg})$ had virtually normal lung allografts without any significant pathology on day 126 (Figure 7D). Quantitatively, for CCR4 ${ }^{+/+}$versus CCR $4^{-/}$ recipients with a single pretransplant low dose of CTLA4-Ig, allograft scores were as follows: AR, 100\% versus $0 \%, P=0.008$; lymphocytic bronchiolitis (LB), $100 \%$ versus $0 \% ; P=0.008$; pleural involvement, $60 \%$ versus $0 \%$; $P=0.17$; septal involvement, $80 \%$ versus $0 \%, P=0.04$. Thus, CCR4 deficiency in combination with an initial CTLA4-Ig treatment at the time of transplantation enabled long-term lung allograft accommodation.

\section{Discussion}

Median survival forindividuals with solid organtransplantssuch asliver, kidney, and heartisgreaterthan 10 years; regrettably this falls to less than 5 years for lung transplant recipients (1-6). The Achilles heel for lung transplant is chronic lung allograft dysfunction, which is predominately due to rejection $(7,9,11,47,48)$. 
A

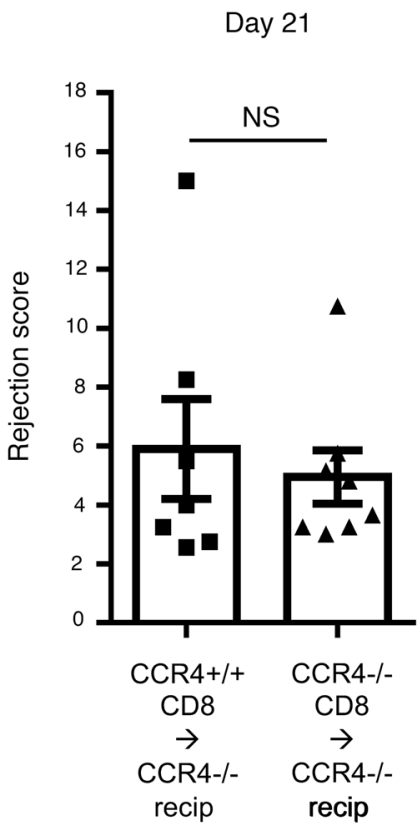

D

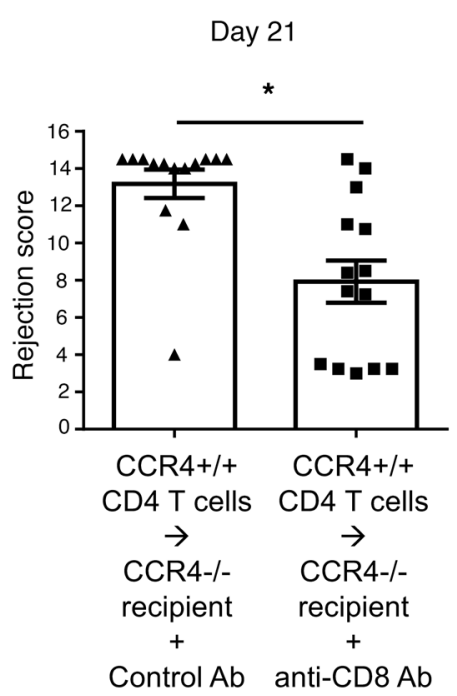

B

Day 21

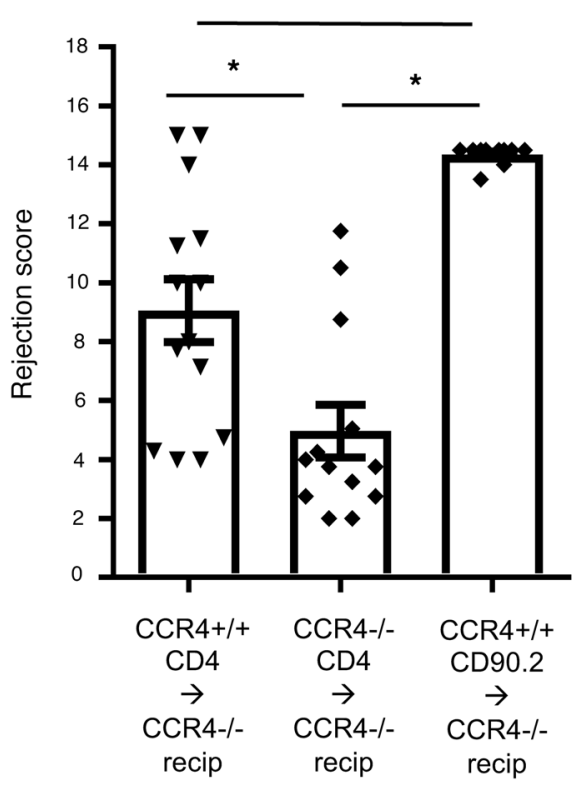

C

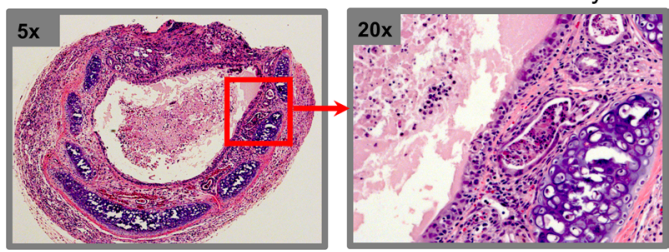

CCR4+/+ CD4+ T cells AT $\rightarrow$ CCR4-/- at Day 21

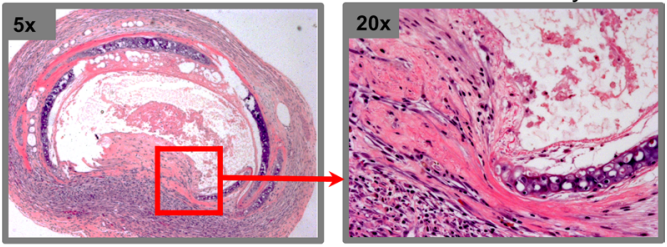

E CCR $4+/+$ CD4 + T cells AT + control $A b \rightarrow C C R-/-$ at Day 21

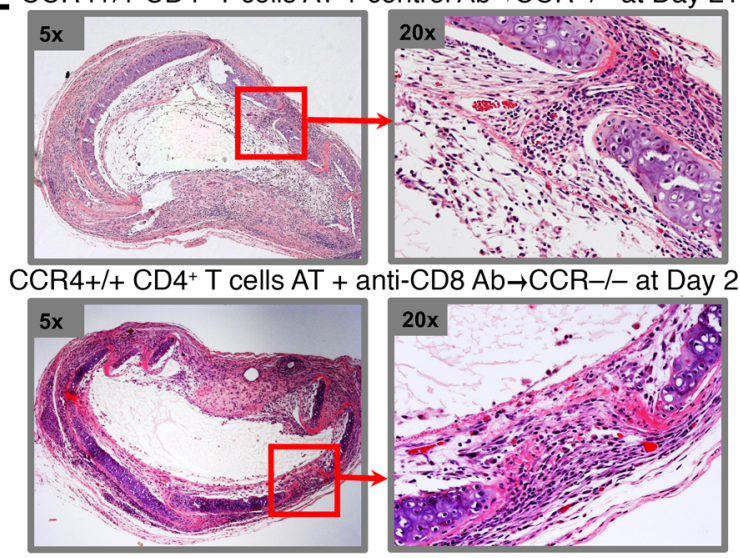

Figure 6. Hierarchy for T cells reestablishing rejection in CCR4-/- recipient mice. CD8 ${ }^{+}\left(5 \times 10^{6}\right), \mathrm{CD}^{+}\left(5 \times 10^{6}\right)$, and $\operatorname{CD} 90.2^{+}\left(1 \times 10^{7}\right) \mathrm{T}$ cells from either CCR4 $4^{-/-}$or CCR4 ${ }^{+/+}$naive mice were transferred to CCR4 ${ }^{-/-}$recipients of BALB/c airway grafts on day 0 , and the allografts were analyzed for rejection scores on day 21. (A and $\mathbf{B})$ Rejection scores of allografts from CCR4 ${ }^{-/-}$recipients (recip) with the transfer of (A) CD8 ${ }^{+}$T cells and (B) CD4+ and CD90.2 T cells. See also Supplemental Figure 5. (C) Representative H\&E staining of day 21 transplanted BALB/C airways from adoptively transferred $\mathrm{CD} 4^{+} \mathrm{T}$ cells from either CCR4 $4^{+/+}$or CCR4 $4^{-/-}$naive mice transferred into CCR4 $4^{-/-}$recipients on day 0 . CCR4 $4^{-/-}$recipients with transferred CCR4 ${ }^{-/-}$ $\mathrm{CD}^{+} \mathrm{T}$ cells have a virtually normal epithelium without fibroblasts obstructing the lumen. Allografts from the CCR4 ${ }^{-/-}$recipients with transferred CCR4 ${ }^{+/+}$CD4 ${ }^{+} \mathrm{T}$ cells have a denuded airway epithelium with a moderate amount of fibroblasts invading the airway lumen. In separate experiments, $\mathrm{CCR}^{+/+} \mathrm{CD}^{+} \mathrm{T}$ cells $\left(5 \times 10^{6}\right)$ were transferred to CCR4 ${ }^{-/-}$recipients with either control Ab or the depleting anti-CD8 Ab delivered on days $-1,7$, and 14 , and the allografts were analyzed for rejection scores on day 21. (D) Rejection scores of allografts from CCR ${ }^{-/-}$recipients with the transfer of $\mathrm{CCR}^{+/+} \mathrm{CD}^{+} \mathrm{T}$ cells with or without anti-CD8 Ab. (E) CCR4 $4^{-1-}$ recipients with transferred CCR4 ${ }^{+/+} \mathrm{CD} 4^{+} \mathrm{T}$ cells plus a control Ab have a loss of airway epithelium with a moderate amount of fibroblasts obstructing the lumen. CCR4 ${ }^{-/-}$recipients with transferred CCR4 $4^{+/+}$CD4 ${ }^{+} \mathrm{T}$ cells plus an anti-CD8 Ab have a denuded airway epithelium and minimal airway invading fibroblasts. Original magnification, $\times 5$ (left panels), $\times 20$ (right panels). Data are representative of 10-16 mice per group. Error bars indicate SEM. Significance was determined by Mann-Whitney $U$ test or Kruskal-Wallis with post hoc Dunn's test where appropriate; ${ }^{*} P<0.05$. 
A

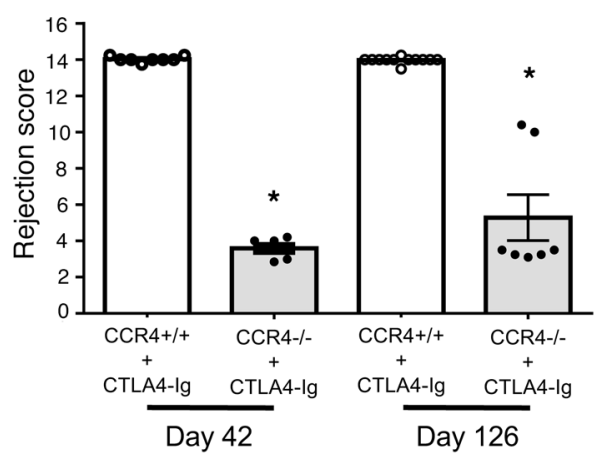

C CCR4+/+ + CTLA4-Ig (0.1 mg pre-lung Tx) day 126

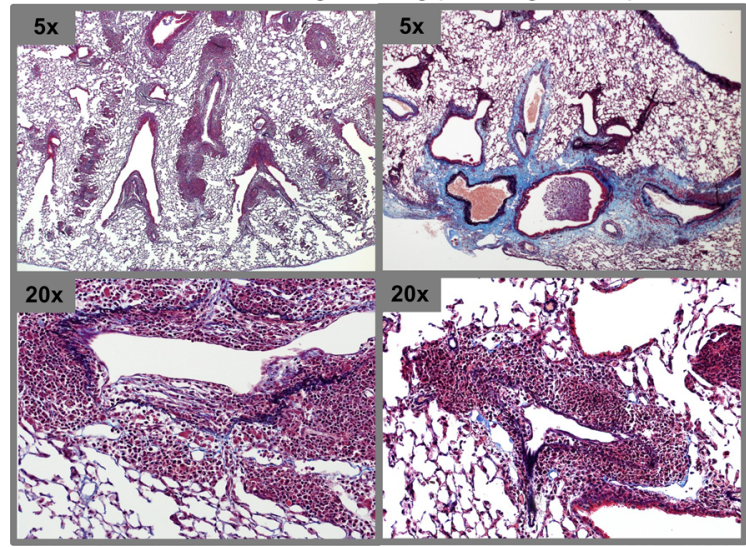

B $\quad$ CCR4-I- + CTLA4-Ig at Day 126

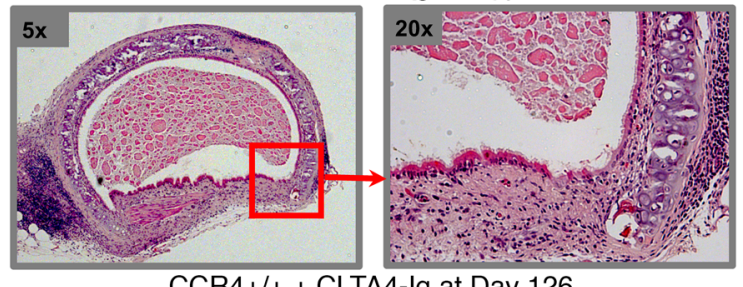

CCR4+/+ + CLTA4-Ig at Day 126

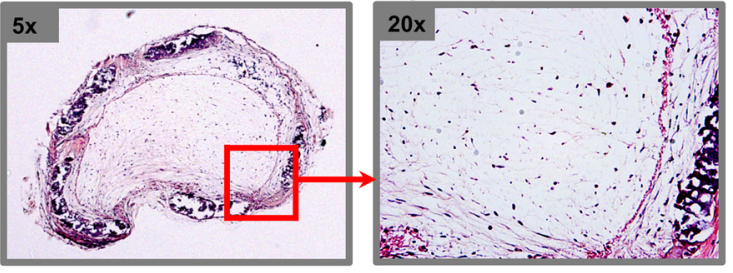

CCR4-I- + CTLA4-lg (0.1 mg pre-lung Tx) day 126

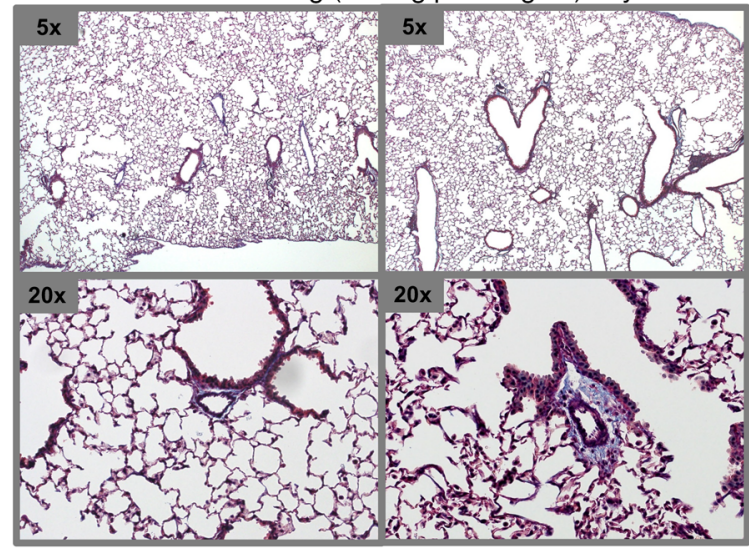

Figure 7. CTLA4-Ig combined with CCR4 ${ }^{-/-}$recipients leads to long-term allograft accommodation in $\mathbf{2}$ models of allograft rejection. CTLA4-Ig given i.p. at 0.2 mg on day 0 prior to airway transplantation, and rejection was evaluated on days 2, 4, and 6 after transplant to CCR4 ${ }^{-/-}$as compared with CCR4 ${ }^{+/+}$. (A) Rejection scores for CTLA4-Ig-treated CCR4 ${ }^{-/-}$and CCR4 ${ }^{+/+}$allograft recipients on days 42 and 126 . See also Supplemental Figure 6. (B) Day 126 representative H\&E staining of airway allografts from CCR4 ${ }^{-/-}$and CCR4 ${ }^{+/+}$recipients given CTLA4-Ig. CTLA4-Ig given to CCR4 ${ }^{-/-}$recipients results in virtually normal airways with intact ciliated epithelium and no fibro-obliteration. CTLA4-Ig given to CCR4 ${ }^{+/}$recipients leads to airways that are rejected, without epithelium, and invaded by fibroblasts causing fibro-obliteration. A section of airway allograft is magnified to show the presence of the epithelial layer in CTLA4-Ig + CCR4 ${ }^{-/-}$and absence of the epithelial layer with fibro-obliteration in CTLA4-Ig + CCR4 ${ }^{+/}$recipients. CCR4 ${ }^{-/-}$and CCR4 $4^{+/}$orthotopic single-lung transplant recipients were given CTLA4-Ig i.p. $(0.1 \mathrm{mg}$ ) on day 0 just prior to transplant (Tx). Original magnification, $\times 5$ (left panels), $\times 20$ (right panels). (C) Day 126 representative elastin trichrome staining shows that CTLA4-Ig given to CCR4 ${ }^{++}$allograft recipients leads to high-grade vascular, airway, and pleural rejection with fibrosis. (D) Day 126 representative elastin trichrome staining shows that CTLA4-Ig given to CCR4-/- allograft recipients leads to virtually normal lung allografts. Data are representative of 4-12 mice per group. Original magnification, $\times 5$ (top panels), $\times 20$ (bottom panels). Error bars indicate SEM. Significance was determined by Mann-Whitney $U$ test; ${ }^{*} P<0.05$.

Unfortunately, our current immunosuppressive strategies have been ineffective for long-term lung allograft accommodation (7, 9, 11, 47, 48), underscoring the need for new insights into lung alloreactivity. Using stringent animal models of airway and lung allograft rejection, we demonstrate that the CCR4-ligand biological axis is central to the allopriming that leads to graft rejection and that CCR4 deficiency dramatically abolishes rejection by restricting nodal homing and subsequent intranodal activation of $\mathrm{CD}^{+}$and $\mathrm{CD} 8^{+} \mathrm{Tn}$ cells. Both CCR4-expressing $\mathrm{CD} 4^{+}$and $\mathrm{CD} 8^{+} \mathrm{T}$ cells are critical for rejection, but $\mathrm{CD}^{+} \mathrm{T}$ cells were pivotal for helping generate alloresponsive cytotoxic $\mathrm{T}$ cells that trigger rapid rejection. Excitingly, CCR4 deficiency combined with low-dose CTLA4-Ig immunotherapy at the time of airway transplantation enabled long-term allograft survival to more than 125 days, over 3 times longer than with CTLA4-Ig alone. This was corroborated using the orthotopic lung transplant model. Thus, this study demonstrates, for the first time to our knowledge, a molecular mechanism involving one specific chemokine axis required for homing and intranodal activation of allospecific $\mathrm{CD}^{+}$and $\mathrm{CD}^{+}$Tn cells that mediate graft rejection. Importantly, inhibition of this chemokine axis with CTLA4-Ig allows for long-term allograft survival. 
SLTs are strategically positioned at the interface between the blood and the lymphatic system and provide an environment that allows for the exchange of antigenic information between cells of the innate and adaptive immune system $(49,50)$. However, the crowding of immune cells in the SLT suggests a role for chemokine guidance in optimizing adaptive immunity (49-51). Many studies suggest that chemokine redundancy limits the usefulness of targeting a single chemokine axis to significantly impair T cell priming (16-22). However, we were struck by the marked elevations of the CCR4 ligands from the allograft SLT. This led to our hypothesis that these chemokines could be key regulators of allopriming.

Importantly, we found that $\mathrm{CCR} 4^{-/-}$allograft recipients had a unprecedented prolonged reduction in rejection when compared with other chemokine axes $(32,33,36)$. This suggests that inhibition of allopriming has the potential to elicit a transplant outcome superior to that resulting from limiting the consequences of alloreactive $\mathrm{T}$ cells that have already been generated $(32,33,36)$. Mechanistically, we ruled out any significant effect of CCR4 expression on donor cells in direct rejection, which focused our attention on recipient CCR4-expressing $\mathrm{T}$ cells during allopriming.

After transplant, draining nodes express CCL17 localized to HEVs and CCL22 from subcapsular sinus mononuclear phagocytes, which is consistent with our adoptive transfer studies demonstrating that CCR4 expression from Tn cells $\left(\mathrm{CD}^{+}\right.$and $\left.\mathrm{CD} 8^{+}\right)$was fundamental for proper homing during allopriming. Furthermore, the expression of CCL22 from paracortical mononuclear phagocytes in close proximity to HEVs, in combination with our data indicating that the few $\mathrm{CCR} 4^{-/-} \mathrm{CD} 4^{+}$and $\mathrm{CD} 8^{+} \mathrm{Tn}$ cells that make it to the SLT are impaired in their ability to shed CD62L, is consistent with a reduction in $\mathrm{CCR} 4^{-/-} \mathrm{Tn}$ cell interactions with APCs surrounding HEVs (17). Collectively, these studies corroborate that the CCR4-ligand biological axis is unique in facilitating homing of both $\mathrm{CD} 4^{+}$and $\mathrm{CD} 8^{+} \mathrm{Tn}$ cells to SLTs and for the intranodal activation needed for optimal generation of alloresponsive $\mathrm{T}$ cells.

Our findings are consistent with the importance of CCR4 expression on other lymphocytes such as NKT cells, as was shown during OVA sensitization (26). More specifically, CCR4 ligands were expressed by APCs within SLTs, which optimized their interactions with NKT cells; that, in turn, licensed the APCs to express CCL3 and CCL4, calling in CCR5 ${ }^{+} \mathrm{CD}^{+} \mathrm{T}$ cells, ultimately generating OVA-specific cytotoxic T lymphocytes (26). Thus, we explored the role of NKT cells during allograft rejection though the use of genetically altered mice that lack NKT cells (i.e., Cd1 $1^{-/-}$mice) as allograft recipients. However, we found no difference in early or late allograft rejection, essentially negating any substantial role of CCR4-expressing NKT cells during rejection.

We noted that $\mathrm{CCR} 4^{-/-}$allograft recipients had a greater reduction in the frequency of $\mathrm{CD} 8^{+} \mathrm{T}$ cells as compared with $\mathrm{CD}^{+} \mathrm{T}$ cells in both allografts and SLTs, which led us to evaluate whether CCR4 expression on $\mathrm{CD}^{+} \mathrm{T}$ cells could lead to $\mathrm{CD} 8^{+} \mathrm{T}$ cell help in generating more allo-injurious $\mathrm{T}$ cells. However, adoptive transfer studies did not establish any $\mathrm{CCR} 4^{+/+} \mathrm{CD} 8^{+} \mathrm{T}$ cell help with regard to rejection. Conversely, we did find that $\mathrm{CCR} 4$ expression on $\mathrm{CD}^{+} \mathrm{T}$ cells was important for $\mathrm{CD} 4^{+} \mathrm{T}$ cell help in generating an alloreactive response causing rejection. Taken together, our adoptive transfer studies demonstrate a hierarchy of $\mathrm{CCR}^{+/+}$lymphocytes with respect to reestablishing rejection in the CCR4 ${ }^{-/-}$recipients $\left(\mathrm{CCR} 4^{+/+} \mathrm{CD} 90.2\right.$ $>\mathrm{CCR}^{+/+} \mathrm{CD}^{+} \mathrm{T}$ cells $>\mathrm{CCR}^{+/+} \mathrm{CD}^{+} \mathrm{T}$ cells). Importantly, perturbing allopriming via CCR4-ligand interruption had physiologic consequences, such as a marked reduction in the clonal expansion of both $\mathrm{CD}^{+}$and $\mathrm{CD}^{+}$alloresponsive $\mathrm{T}$ cells, decreased in vivo DTH response to alloantigens, and diminished cytotoxic T cell downstream pathways at the site of the allograft. Taken together with other studies (31-34, 52), our study suggests that CCR4-ligand interaction is a linchpin in the alloresponse and inhibition of this single chemokine axis can limit allograft rejection.

Rodent models of allograft rejection have demonstrated that the most effective therapy that allows for long-term allograft acceptance was combined costimulatory blockade involving anti-CD154 and CTLA4Ig (46). Unfortunately, human studies involving anti-CD154 led to high rates of vessel thrombosis $(53,54)$, quickly dampening the hopes for a strategy to achieve long-term accommodation. However, our data suggest that the inhibition of CCR4-ligand interactions is an alternate method to limit costimulation between CD4 ${ }^{+}$ Tn cells and APCs. Thus, we tested the combination of a short course of CTLA4-Ig with either the CCR4 ${ }^{-/-}$ or $\mathrm{CCR} 4^{+/+}$recipients and found that $\mathrm{CCR} 4^{-/-}$recipients had virtually normal airway allografts on day 126 , while $\mathrm{CCR} 4^{+/+}$recipients completely rejected allografts by day 42 . Importantly, this was reproducible in the vascularized orthotopic single-lung transplant model, as CTLA4-Ig given to CCR $4^{-/-}$recipients resulted in a virtually normal lung allograft on day 126.

Interestingly, 2 studies have evaluated CCR4-expressing Tregs in cardiac allograft models that develop tolerance via the combination of inhibiting CD40-CD154 interactions (e.g., anti-CD154 Ab) with a donor 
splenocyte transfusion (DST) $(41,42)$. In the first study, the Treg expression marker Foxp3 was found to be elevated in allografts from recipients with tolerance, as compared with allografts with long-term accommodation (e.g., $\mathrm{CD} 28^{-/-}$recipient plus anti-ICOS mAb therapy) or allografts undergoing acute rejection (e.g., no immunosuppression) (41). Importantly, when the tolerizing therapy (anti-CD154 with DST) was applied to $\mathrm{CCR} 4^{-/-}$and $\mathrm{CCR} 4^{+/+}$recipients, the allografts' Foxp3 expression from the $\mathrm{CCR} 4^{-/-}$recipients was significantly lower (41), which translated into a reduction in allograft survival (41). The second study involved a similar cardiac tolerance model and found that CCR7-expressing plasmacytoid dendritic cells move from the allograft to the lymph node, then secrete CCL17 and TGF- $\beta$. CCL17 then recruits conventional T cells expressing CCR4, while TGF- $\beta$ induces these $\mathrm{T}$ cells into Tregs, allowing tolerance to occur (55). Importantly, anti-CD154 and the DST could not provoke tolerance when delivered to the CCR4 ${ }^{-1}$ allograft recipients (55). Another study involving an islet cell transplant model that is exquisitely sensitive to Treg therapy for tolerance (56) found CCR4 expression to be important for Treg movement from the blood to the allograft, where they become activated and then express CCR7, IL-10, and TGF- $\beta$. The cytokines inhibited dendritic cell migration from the allograft to the draining lymph node, while CCR7 expression led to Treg homing to the draining node, which reduced alloresponsive T cells (57). In a fully mismatched model of cardiac transplantation, the use of $\mathrm{CCR} 4^{-/-}$recipients trended toward prolonged allograft survival $(P=0.05$; ref. 58), while addition of the immunosuppressive drug gallium nitrate (GN) led to a reduction in allograft-infiltrating lymphocytes and significantly prolonged allograft survival (58). Collectively, these studies in combination with our results demonstrate that CCR4 expression from $\mathrm{CD}^{+} \mathrm{T}$ cells (conventional and Tregs) may have disparate properties depending on the allograft environment. More specifically, CCR4 expression is important for Tregs to induce tolerance at the nodal and allograft levels. However, in an accommodating environment, CCR4-expressing CD4 ${ }^{+} \mathrm{T}$ cells are important for homing and intranodal trafficking that generate alloresponsive $\mathrm{T}$ cells as well as Foxp3 expression within SLTs. Thus, it is conceivable that CCR4 inhibition in human lung transplant recipients of standard triple immunosuppressive therapy could reduce alloresponsive T cells while decreasing Foxp3 expression within SLTs. This should reduce and delay rejection, thereby promoting long-term accommodation. However, this may occur at the expense of giving the lung allograft any chance of cultivating donor-specific tolerance.

In conclusion, we have found that interrupting allopriming by manipulating CCR4-ligand interactions disrupts homing of both $\mathrm{CD}^{+}$and $\mathrm{CD} 8^{+}$Tn cells to SLTs, as well as their activation within the node. This leads to a dramatic reduction in clonal expansion of alloresponsive T cells, DTH response, and cytotoxic mediators, which markedly attenuates allograft rejection. Moreover, the combination of CCR4-ligand inhibition with CTLA4-Ig blockade leads to long-term accommodation that outperforms the best known combination of costimulatory blockade (anti-CD154 and CTLA4-Ig; ref. 46). Overall, this study suggests that altering events prior to allorecognition, the so-called signal 0, via the CCR4-ligand biological axis may be a therapeutic option to prolong allograft survival and warrants further investigation in human organ transplantation.

\section{Methods}

Animals. WT female BALB/c $\left(\mathrm{H}-2 \mathrm{~K}^{\mathrm{d}}\right)$, C57BL/6 $\left(\mathrm{H}-2 \mathrm{~K}^{\mathrm{b}}\right)$, and B6(C)-Cd1d1 $1^{\mathrm{tm} 1.2 \mathrm{Aben} / \mathrm{J}}\left(\mathrm{NKT}^{-/-}\right)$mice, $8-10$ weeks old, were purchased from the Jackson Laboratory. CCR $4^{-/-}$mice on a C57BL/ 6 background were generated in house.

Murine rejection models. The heterotopic subcutaneous tracheal/airway transplantation model of alloreactivity involves the most stringent $\mathrm{MHC}$ class I- and II-disparate combination mismatch found in mice: BALB/c $\left(\mathrm{H}-2^{\mathrm{d}}\right)$ tracheas transplanted subcutaneously into the upper backs of C57BL/6 $\left(\mathrm{H}-2^{\mathrm{b}}\right)$ mice (allografts) and C57BL/6 tracheas transplanted subcutaneously into the backs of C57BL/6 mice (syngeneic control) $(32,33,36)$. Each mouse was subcutaneously transplanted with 2 tracheas. The small molecule CCR4 antagonist C 021 dihydrochloride (catalog 3581, Tocris Bio-Techne) was resuspended in sterile DMSO to $100 \mathrm{mg} / \mathrm{ml}$ and diluted further in $1 \times$ PBS to be administered as i.p. injections at $50 \mathrm{mg} / \mathrm{kg}$ daily starting on day -1 prior to tracheal transplantation until day 14 when allografts were harvested for rejection analysis. For long-term experiments, CTLA4-Ig treatment (Bristol-Myers Squibb) was given as 0.2-mg i.p. injection on day 0 prior to tracheal transplantation and on days 2, 4, and 6 thereafter.

The orthotopic left single-lung transplant model involved BALB/c left lungs transplanted into CCR $4^{+/+}$ or $\mathrm{CCR} 4^{-/-}$recipients in combination with a single preoperative dose of $0.1 \mathrm{mg}$ CTLA4-Ig using a modification of the previously described rodent left lung transplant procedure $(36,52)$. Briefly, donor BAL$\mathrm{B} / \mathrm{c}$ mice were anesthetized, intubated, and ventilated; the left lung was harvested; and Teflon cuffs were 
secured on the pulmonary artery, vein, and bronchus, then covered with soaked gauze pads on ice. The recipient mice are anesthetized, intubated, and ventilated. A 2-cm incision was made between 3 and 4 ribs on the left and, a 1/4-binder clip was placed to expose the posterior hilum. Appropriate dissection of the hilum components included ligation and clamping after heparin delivery. A donor lung was inserted using the cuff technique via a 10.0 Ethilon suture. Incision closure involved a v6-0 surgical suture. During the procedure, $1 \mathrm{cc}$ of saline was administered subcutaneously and postoperatively. The animals were placed in cages on warm water mattresses until they recovered from anesthesia. Buprenorphine $(0.1 \mathrm{mg} / \mathrm{kg}$, i.p. $)$ was given every 12 hours while monitoring for pain. Sutures were removed on postoperative day 7 .

Histopathological evaluation of airway and lung transplants. Airway and lung graft tissues were fixed overnight in $4 \%$ paraformaldehyde, processed, and paraffin embedded by the Translational Pathology Core Laboratory at UCLA, and sectioned and stained with H\&E or elastin trichrome. Three independent reviewers blinded to the experimental protocol calculated the degree of airway injury using the histological scoring system as described previously $(32,33,36)$. All qualitative histological changes were evaluated, and the total murine rejection score was calculated based on 4 pathological criteria: (i) airway lining epithelial loss, (ii) deposition of extracellular matrix, (iii) leukocyte infiltration, and (iv) luminal fibro-obliteration due to granulation tissue formation and/or fibrosis. Each process was scored on a scale of 0 to 4 ( $0=$ normal, $1=$ mild, $2=$ moderate, $3=$ severe, and $4=$ very severe) and added together for a total rejection score. Lung allograft rejection scores included acute rejection, lymphocytic bronchiolitis, and pleural and septal rejection based on established criteria $(59,60)$. Images were taken with a Zeiss Axioskop 2 Plus microscope and analyzed with AxioVision 4.2 imaging software. Images were taken at $\times 5$ to show whole pathology of tracheas and at $\times 20$ to amplify the presence or absence of epithelial cells and/or fibro-obliteration of the airway allograft lumen, as well as different aspects of lung rejection and fibrosis.

IHC. Staining of paraffin-embedded lymph node samples was performed using the VECTASTAIN ABC Standard kits (Vector Laboratories) as previously described (61). After deparaffinization and antigen retrieval in sodium citrate buffer ( $\mathrm{pH}$ 6.0), endogenous peroxidase was quenched with $3 \%$ hydrogen peroxide. Tissues were incubated in appropriate blocking serum, and endogenous biotin was blocked with an avidin/biotin blocking kit (Vector Laboratories). Slides were incubated overnight with primary $\mathrm{Abs}$ at $4^{\circ} \mathrm{C}$. The primary Abs for rat polyclonal anti-mouse CCL17 (MAB529) were purchased from R\&D Systems Inc., and rabbit monoclonal anti-mouse CCL22 (ab124768) was purchased from Abcam. Specific labeling was detected with a biotinylated specific secondary $\mathrm{Ab}$ and application of horseradish peroxidase-conjugated avidin-biotin, followed by visualization with DAB solution (Vector Laboratories).

Total RNA isolation and $q P C R$. Total cellular RNA from transplanted airways (previously frozen in liquid nitrogen) was isolated using TRIzol (Thermo Fisher Scientific) and chloroform treatment, precipitated with isopropanol, washed twice with 75\% ethanol, and resuspended in DEPC-treated water. Total RNA concentration was determined using a NanoDrop 2000 UV-Vis spectrophotometer (Thermo Fisher Scientific), and $2 \mu \mathrm{g}$ total RNA was DNase treated to remove genomic DNA contamination and reversed transcribed into cDNA using TaqMan reverse transcription reagents (Thermo Fisher Scientific). Specific targets were amplified on a StepOnePlus qPCR machine (Thermo Fisher Scientific) using TaqMan gene expression assays: perforin 1 (Mm00812512_m1), Fas ligand (Mm00438864_m1), Foxp3 (Mm00475156_m1), and eukaryotic $18 \mathrm{~S}(4319413 \mathrm{E})$ as an endogenous control. RNA expression levels were compared with WT allografts using the $2^{\Delta \Delta \mathrm{Ct}}$ method (62), and data are presented as fold change.

Protein analysis by Luminex. Draining lymph nodes and heterotopically transplanted airways from recipient animals were surgically removed on different days (7, 14, and 21 days) and snap frozen in liquid nitrogen. Frozen tissues were homogenized in $1 \times$ PBS supplemented with complete protease inhibitor cocktail (Roche), sonicated on ice for 10 seconds, centrifuged at $13,000 \mathrm{rpm}$ to remove any cellular debris, and analyzed by Luminex labeling kits (R\&D Systems) according to the manufacturer's instructions.

Flow cytometry analysis of draining lymph nodes and airway allografts. Single-cell suspensions were prepared from harvested axillary/brachial lymph nodes or airways using a method described previously $(32,33,36)$. Briefly, tissues were put through a steel mesh by using a plunger, and cells were collected in RPMI-1640 medium (Mediatech) supplemented with L-glutamine, penicillin/streptomycin, and HEPES buffer. Red blood cells were lysed using ACK (ammonium-chloride-potassium) lysing buffer and washed twice in $1 \times$ PBS plus $0.1 \%$ FBS. Live cells counted with a hemocytometer using trypan blue (Sigma-Aldrich) and $1 \times$ $10^{6}$ cells were stained with different cell surface-conjugated anti-mouse Abs: hamster CD3a-PerCP, CD3aFITC, rat CD4-FITC, CD4-APC, CD8-FITC, CD8a-APC, CD44-APC, and CD62L-PE (BD Biosciences). 
Cell suspensions were acquired using a FACSCalibur (BD Biosciences) and analyzed with CellQuest software (BD Biosciences), and data were expressed and compared as frequencies of selected subpopulations. The specific gating strategies for each experiment are explained in figure legends where appropriate.

Flow cytometry IFN- $\gamma$ cytokine secretion assay. A mixture of draining lymph node (axillary/brachial) cells from $\mathrm{CCR} 4^{-/-}$and $\mathrm{CCR} 4^{+/+}$airway allograft recipients on day 7 was collected for ex vivo stimulation. Single-cell suspension was prepared as described above, and $1 \times 10^{6}$ recipient cells from $\mathrm{CCR}_{4}{ }^{-/}$and $\mathrm{CCR} 4^{+/+}$allograft recipients and naive nontransplanted CCR $4^{-/-}$and $\mathrm{CCR} 4^{+/+}$mice were stimulated in the presence of either RPMI 1640 supplemented with 5\% FBS alone or $2 \times 10^{6}$ irradiated and digested BALB/c splenocytes. After 16 hours of incubation at $37^{\circ} \mathrm{C}$ and $5 \% \mathrm{CO}_{2}$, cells were washed and analyzed using the flow cytometry IFN- $\gamma$ cytokine secretion (FCIS) assay (Miltenyi Biotec) via flow cytometry analysis on a minimum of 250,000 total events. The cells were stained for 7-AAD (to exclude dead cells in the PerCP channel), B220-PerCP (to exclude B cells), CD3-FITC, IFN- $\gamma-\mathrm{PE}$, and either CD4-APC or CD8-APC (to measure percent cell frequency of alloresponsive T cells). The coefficient of variation with FCIS is $5 \%-15 \%$, with a lower limit of detection of $0.01 \%$ or $1 / 10,000$ IFN- $\gamma$-secreting cells (63).

In vivo DTH response. Recipient animals $\left(\mathrm{CCR} 4^{+/+}\right.$and $\left.\mathrm{CCR} 4^{-/-}\right)$after airway transplant on day 7 were challenged with BALB/c alloantigens in a DTH response using the pinnae swelling assay (64). Briefly, at 7 days after transplant, a 10- $\mu 1$ volume of irradiated single-cell suspension of digested BALB/c splenocytes $\left(7.5 \times 10^{6}\right.$ total cells in saline) was injected into the right ear pinna by using a 30 -gauge needle and a Hamilton syringe (Hamilton). The left control ear pinna received $10 \mu 1$ sterile saline solution. Ear swelling was measured 48 hours later with a Mitutoyo 7326 Micrometer (Schlessinger Tools), and the results were expressed as the mean swelling of challenge ear minus the mean swelling of control ear (units, mm). All challenges and measurements were performed under light anesthesia (isoflurane).

Adoptive transfer experiments. Total $\left(\mathrm{CD} 90.2^{+}\right), \mathrm{CD}^{+}$or $\mathrm{CD}^{+} \mathrm{T}$ cells were purified from spleens of naive $\mathrm{CCR}^{+/+}$or $\mathrm{CCR} 4^{-/-}$mice by positive selection using CD90.2, CD4(L3T4), or CD8(Ly-2) T cell MicroBead Isolation Kits, respectively (Miltenyi Biotec) following the manufacturer's instructions. Briefly, animal spleens were surgically extracted, pushed through metal mesh to remove cells, and washed twice in MACS rinsing buffer supplemented with $2 \%$ BSA. Total cells were counted using crystal violet; stained with MicroBeads; and purified using positive selection by magnetic LS columns (Miltenyi Biotec), washed, and resuspended in sterile saline. After selection, $1 \times 10^{7} \mathrm{CD} 90.2,5 \times 10^{6} \mathrm{CD}^{+}$, or $5 \times 10^{6} \mathrm{CD}^{+}$live $\mathrm{T}$ cells (as determined by trypan blue staining) were injected i.v. into each mouse prior to subcutaneous transplantation with BALB/c tracheas. Allograft rejection was analyzed on day 21 by histopathological rejection scoring analysis as previously described. Additionally, we performed in vivo $\mathrm{CD}^{+} \mathrm{T}$ cell depletion experiments. CCR4 ${ }^{-/-}$mice were given an i.p. injection of either $0.25 \mathrm{mg}$ anti-CD8 Ab (clone 53-6.72, BioXCell) or control isotype $\mathrm{Ab}$ (clone $2 \mathrm{~A} 3$, BioXCell) on day -1 of heterotopic BALB/c transplant and repeated the experiments on days 7 and 14 after transplant with the addition of a transfer of $5 \times 10^{6} \mathrm{CD}^{+}$ $\mathrm{T}$ cells injected immediately prior to the heterotopic transplant procedure. Allografts were isolated on day 21 and evaluated for rejection.

$T$ cell trafficking. Splenic total T cells were purified from naive $\mathrm{CCR} 4^{+/+}$or $\mathrm{CCR} 4^{-/-}$animals and labeled with $4.0 \mu \mathrm{M}$ CFSE (Thermo Fisher Scientific) or $0.25 \mu \mathrm{M}$ CFSE, respectively, according to the manufacturer's instructions. Stained single-cell suspensions were washed 3 times in cold $1 \times \mathrm{PBS} / 1 \% \mathrm{BSA}$ to remove residuals of CFSE, resuspended in sterile saline, and mixed as a 1:1 ratio of live cells as determined by trypan blue counts. $10 \times 10^{6}$ live total T cells per $150 \mu$ of sterile saline were injected into (i) day 7 CCR $4^{+/+}$or $\mathrm{CCR}^{-/-}$recipients transplanted with $\mathrm{BALB} / \mathrm{c}$ airways and (ii) day $7 \mathrm{CCR} 4^{+/+}$recipients transplanted with C57BL/6 airways (isogeneic). Axillary/brachial lymph nodes were removed after 18 hours and analyzed by flow cytometry for different $\mathrm{T}$ cell subpopulations.

Statistics. Data were analyzed using GraphPad Prism 7.00 statistical software. Group comparisons were evaluated by unpaired 2-tailed $t$ test or Mann-Whitney $U$ test where appropriate for statistical significance and reported as mean \pm SEM. Multiple comparisons were performed with the Kruskal-Wallis and post hoc Dunn's test. $P<0.05$ was considered statistically significant.

Study approval. All animals were housed in the animal husbandry facilities at UCLA, and experiments were conducted under a protocol approved by the UCLA Division of Laboratory Animal Medicine in accordance with federal, state, and local regulations. 


\section{Author contributions}

VP, MPK, and JAB designed the experiments; VP, YYX, RK, MPK, and JAB performed the experiments. VP, SSW, ALG, SXS, MCF, CMH, DMS, JPL, MPK, DGB, and JAB analyzed the data. VP and JAB wrote the manuscript.

\section{Acknowledgments}

We would like to thank Elaine Reed and Yael Korin for assistance with learning the FCIS assay. We also thank Shirin Birjandi, Angela Wong, and Wing Yi Lung for their valuable suggestions and assistance regarding experimental procedures. This study was supported in part by NIH funding that includes R01 HL112990 and P01HL108793-06 to JAB.

Address correspondence to: John A. Belperio, UCLA, David Geffen School of Medicine, Division of Pulmonary \& Critical Care Medicine, 650 Charles E. Young Drive South, Center for the Health Sciences, 52-243, Los Angeles, California 90095. Phone: 310.794.1992; Email: jbelperio@mednet.ucla.edu.

1. Chambers DC, et al. The Registry of the International Society for Heart and Lung Transplantation: Thirty-Fourth Adult Lung and Heart-Lung Transplantation Report-2017. Focus theme: allograft ischemic time. J Heart Lung Transplant. 2017;36(10):1047-1059.

2. Hart A, et al. OPTN/SRTR 2016 annual data report: kidney. Am J Transplant. 2018;18(suppl 1):18-113.

3. Kim WR, et al. OPTN/SRTR 2016 annual data report: liver. Am J Transplant. 2018;18(suppl 1):172-253.

4. Lodhi SA, Lamb KE, Meier-Kriesche HU. Solid organ allograft survival improvement in the United States: the long-term does not mirror the dramatic short-term success. Am J Transplant. 2011;11(6):1226-1235.

5. Yusen RD, et al. The Registry of the International Society for Heart and Lung Transplantation: Thirty-Third Adult Lung and Heart-Lung Transplant Report-2016. Focus theme: primary diagnostic indications for transplant. J Heart Lung Transplant. 2016;35(10):1170-1184.

6. Rana A, et al. Survival benefit of solid-organ transplant in the United States. JAMA Surg. 2015;150(3):252-259.

7. Belperio JA, Weigt SS, Fishbein MC, Lynch JP. Chronic lung allograft rejection: mechanisms and therapy. Proc Am Thorac Soc. 2009;6(1):108-121.

8. Shino MY, et al. Impact of allograft injury time of onset on the development of chronic lung allograft dysfunction after lung transplantation. Am J Transplant. 2017;17(5):1294-1303.

9. Shino MY, et al. CXCR3 ligands are associated with the continuum of diffuse alveolar damage to chronic lung allograft dysfunction. Am J Respir Crit Care Med. 2013;188(9):1117-1125.

10. Weigt SS, DerHovanessian A, Wallace WD, Lynch JP, Belperio JA. Bronchiolitis obliterans syndrome: the Achilles' heel of lung transplantation. Semin Respir Crit Care Med. 2013;34(3):336-351.

11. Weigt SS, et al. Chronic allograft rejection: epidemiology, diagnosis, pathogenesis, and treatment. Semin Respir Crit Care Med. 2010;31(2):189-207.

12. Weigt SS, et al. Gene expression profiling of bronchoalveolar lavage cells preceding a clinical diagnosis of chronic lung allograft dysfunction. PLoS ONE. 2017;12(1):e0169894.

13. Freese DK, Snover DC, Sharp HL, Gross CR, Savick SK, Payne WD. Chronic rejection after liver transplantation: a study of clinical, histopathological and immunological features. Hepatology. 1991;13(5):882-891.

14. Matas AJ. Risk factors for chronic rejection — a clinical perspective. Transpl Immunol. 1998;6(1):1-11.

15. Tullius SG, Tilney NL. Both alloantigen-dependent and -independent factors influence chronic allograft rejection. Transplantation. 1995;59(3):313-318.

16. Bajénoff M, et al. Stromal cell networks regulate lymphocyte entry, migration, and territoriality in lymph nodes. Immunity. 2006;25(6):989-1001.

17. Bousso P, Robey E. Dynamics of CD8+ T cell priming by dendritic cells in intact lymph nodes. Nat Immunol. 2003;4(6):579-585.

18. Lindquist RL, et al. Visualizing dendritic cell networks in vivo. Nat Immunol. 2004;5(12):1243-1250.

19. Mempel TR, Henrickson SE, Von Andrian UH. T-cell priming by dendritic cells in lymph nodes occurs in three distinct phases. Nature. 2004;427(6970):154-159.

20. Miller MJ, Hejazi AS, Wei SH, Cahalan MD, Parker I. T cell repertoire scanning is promoted by dynamic dendritic cell behavior and random T cell motility in the lymph node. Proc Natl Acad Sci USA. 2004;101(4):998-1003.

21. Miller MJ, Wei SH, Cahalan MD, Parker I. Autonomous T cell trafficking examined in vivo with intravital two-photon microscopy. Proc Natl Acad Sci USA. 2003;100(5):2604-2609.

22. Miller MJ, Wei SH, Parker I, Cahalan MD. Two-photon imaging of lymphocyte motility and antigen response in intact lymph node. Science. 2002;296(5574):1869-1873.

23. Huang JH, et al. Requirements for T lymphocyte migration in explanted lymph nodes. J Immunol. 2007;178(12):7747-7755.

24. Castellino F, Huang AY, Altan-Bonnet G, Stoll S, Scheinecker C, Germain RN. Chemokines enhance immunity by guiding naive CD8+ T cells to sites of CD4+ T cell-dendritic cell interaction. Nature. 2006;440(7086):890-895.

25. Hugues S, et al. Dynamic imaging of chemokine-dependent CD8+ T cell help for CD8+ T cell responses. Nat Immunol. 2007;8(9):921-930.

26. Semmling V, et al. Alternative cross-priming through CCL17-CCR4-mediated attraction of CTLs toward NKT cell-licensed DCs. Nat Immunol. 2010;11(4):313-320.

27. Priyadharshini B, Greiner DL, Brehm MA. T-cell activation and transplantation tolerance. Transplant Rev (Orlando). 2012;26(3):212-222. 
28. Song K, et al. Characterization of subsets of CD4+ memory $\mathrm{T}$ cells reveals early branched pathways of $\mathrm{T}$ cell differentiation in humans. Proc Natl Acad Sci USA. 2005;102(22):7916-7921.

29. Brandes M, Legler DF, Spoerri B, Schaerli P, Moser B. Activation-dependent modulation of B lymphocyte migration to chemokines. Int Immunol. 2000;12(9):1285-1292.

30. Ross R, et al. Mouse langerhans cells differentially express an activated T cell-attracting CC chemokine. J Invest Dermatol. 1999;113(6):991-998.

31. Belperio JA, et al. Role of CXCR2/CXCR2 ligands in vascular remodeling during bronchiolitis obliterans syndrome. J Clin Invest. 2005;115(5):1150-1162.

32. Belperio JA, et al. Critical role for the chemokine MCP-1/CCR2 in the pathogenesis of bronchiolitis obliterans syndrome. J Clin Invest. 2001;108(4):547-556.

33. Belperio JA, et al. Critical role for CXCR3 chemokine biology in the pathogenesis of bronchiolitis obliterans syndrome. J Immunol. 2002;169(2):1037-1049.

34. Keane MP, et al. IL-13 is pivotal in the fibro-obliterative process of bronchiolitis obliterans syndrome. J Immunol. 2007;178(1):511-519.

35. Lama VN, et al. Models of lung transplant research: a consensus statement from the National Heart, Lung, and Blood Institute workshop. JCI Insight. 2017;2(9):e93121.

36. Belperio JA, et al. CXCR2/CXCR2 ligand biology during lung transplant ischemia-reperfusion injury. J Immunol. 2005;175(10):6931-6939.

37. Hu Z, Lancaster JN, Sasiponganan C, Ehrlich LI. CCR4 promotes medullary entry and thymocyte-dendritic cell interactions required for central tolerance. J Exp Med. 2015;212(11):1947-1965.

38. Chang AL, et al. CCL2 produced by the glioma microenvironment is essential for the recruitment of regulatory $\mathrm{T}$ cells and myeloid-derived suppressor cells. Cancer Res. 2016;76(19):5671-5682.

39. Gilet J, et al. Role of CCL17 in the generation of cutaneous inflammatory reactions in Hu-PBMC-SCID mice grafted with human skin. J Invest Dermatol. 2009;129(4):879-890.

40. Larsen CP, Morris PJ, Austyn JM. Migration of dendritic leukocytes from cardiac allografts into host spleens. A novel pathway for initiation of rejection. J Exp Med. 1990;171(1):307-314.

41. Lee I, Wang L, Wells AD, Dorf ME, Ozkaynak E, Hancock WW. Recruitment of Foxp3+ T regulatory cells mediating allograft tolerance depends on the CCR4 chemokine receptor. J Exp Med. 2005;201(7):1037-1044.

42. Ochando JC, et al. Alloantigen-presenting plasmacytoid dendritic cells mediate tolerance to vascularized grafts. Nat Immunol. 2006;7(6):652-662.

43. Miyajima M, et al. Early acceptance of renal allografts in mice is dependent on foxp3(+) cells. Am J Pathol. 2011;178(4):1635-1645

44. Bueno V, Pestana JO. The role of CD8+ T cells during allograft rejection. Braz J Med Biol Res. 2002;35(11):1247-1258.

45. Kalish RS, Askenase PW. Molecular mechanisms of CD8+ T cell-mediated delayed hypersensitivity: implications for allergies, asthma, and autoimmunity. J Allergy Clin Immunol. 1999;103(2 pt 1):192-199.

46. Sachs DH, Kawai T, Sykes M. Induction of tolerance through mixed chimerism. Cold Spring Harb Perspect Med. 2014;4(1):a015529.

47. Belperio JA, Lake K, Tazelaar H, Keane MP, Strieter RM, Lynch JP. Bronchiolitis obliterans syndrome complicating lung or heart-lung transplantation. Semin Respir Crit Care Med. 2003;24(5):499-530.

48. Weigt SS, et al. Gene expression profiling of bronchoalveolar lavage cells during aspergillus colonization of the lung allograft Transplantation. 2018;102(6):986-993.

49. Misslitz A, Bernhardt G, Förster R. Trafficking on serpentines: molecular insight on how maturating T cells find their winding paths in the thymus. Immunol Rev. 2006;209:115-128.

50. Weninger W, von Andrian UH. Chemokine regulation of naïve T cell traffic in health and disease. Semin Immunol. 2003;15(5):257-270.

51. Guerder S, Matzinger P. A fail-safe mechanism for maintaining self-tolerance. J Exp Med. 1992;176(2):553-564.

52. Belperio JA, et al. The role of the CC chemokine, RANTES, in acute lung allograft rejection. J Immunol. 2000;165(1):461-472.

53. Buhler L, Alwayn IP, Appel JZ, Robson SC, Cooper DK. Anti-CD154 monoclonal antibody and thromboembolism. Transplantation. 2001;71(3):491.

54. Kawai T, Andrews D, Colvin RB, Sachs DH, Cosimi AB. Thromboembolic complications after treatment with monoclonal antibody against CD40 ligand. Nat Med. 2000;6(2):114.

55. Okada T, Cyster JG. CC chemokine receptor 7 contributes to Gi-dependent T cell motility in the lymph node. J Immunol. 2007;178(5):2973-2978.

56. Webster $\mathrm{KE}$, et al. In vivo expansion of $\mathrm{T}$ reg cells with IL-2-mAb complexes: induction of resistance to EAE and long-term acceptance of islet allografts without immunosuppression. J Exp Med. 2009;206(4):751-760.

57. Zhang N, et al. Regulatory $\mathrm{T}$ cells sequentially migrate from inflamed tissues to draining lymph nodes to suppress the alloimmune response. Immunity. 2009;30(3):458-469.

58. Hüser N, et al. CCR4-deficient mice show prolonged graft survival in a chronic cardiac transplant rejection model. Eur J Immunol. 2005;35(1):128-138.

59. Ofek E, et al. Restrictive allograft syndrome post lung transplantation is characterized by pleuroparenchymal fibroelastosis. Mod Pathol. 2013;26(3):350-356.

60. Stewart S, et al. Revision of the 1996 working formulation for the standardization of nomenclature in the diagnosis of lung rejection. J Heart Lung Transplant. 2007;26(12):1229-1242.

61. Palchevskiy V, et al. Immune response CC chemokines CCL2 and CCL5 are associated with pulmonary sarcoidosis. Fibrogenesis Tissue Repair. 2011;4:10.

62. Livak KJ, Schmittgen TD. Analysis of relative gene expression data using real-time quantitative PCR and the 2(-Delta Delta C(T)) Method. Methods. 2001;25(4):402-408.

63. Korin YD, et al. A novel flow assay for the detection of cytokine secreting alloreactive T cells: application to immune monitoring Hum Immunol. 2005;66(11):1110-1124

64. Lausch RN, Monteiro C, Kleinschrodt WR, Oakes JE. Superiority of antibody versus delayed hypersensitivity in clearance of HSV-1 from eye. Invest Ophthalmol Vis Sci. 1987;28(3):565-570. 